This is a post-print (author's final draft) of a chapter in M.Barbieri (Ed.) (2008). The Codes of Life. The Rule of Macroevolution (pp. 395-434). Berlin: Springer. [Original page numbers between square brackets]. Details of the definitive version are available at http://www.springer.com/life+sciences/evolutionary+\%26+developmental +biology/book/978-1-4020-6339-8

\title{
The Musical Code between Nature and Nurture: Ecosemiotic and Neurobiological Claims
}

\section{Mark Reybrouck}

\begin{abstract}
[395] This contribution is about sense-making in music. In an attempt to bring together such diverging fields as semiotics and neurobiology, it argues for a processual approach to music which conceives of "music users" as organisms that "cope" with their environment. It is a position which calls forth ecological and epistemological assumptions and which stresses the importance of a conception of music-as-dealt-with rather than a static conception of music as structure or artefact. As such, it considers music as a sounding and temporal art which appeals to lower-level mechanisms of reactivity as well as to acquired mechanism of sense-making which are the outcome of a learning history. It is argued, further, that there is a continuum between lower level sensory processing and higher-order cognitive elaboration. The musical code, accordingly, holds a hybrid position between innate and wired-in dispositions and higher-level cognitive processing mechanisms. The very concept of code, further, is given some theoretical grounding as well as empirical evidence from the domains of psychophysics, psychobiology and neurobiology.
\end{abstract}

\section{Introduction}


This contribution is about musical sense-making. It argues for an interdisciplinary approach to the process of "dealing with music" in an attempt to bring together such diverging fields as semiotics and neurobiology. Its major aim is not to present a theoretical and empirical state of the art (see Reybrouck 2001a, b, 2003b, 2004, 2005a, b) but to provide an operational approach that has both descriptive and explanatory power. As such, it argues for a broadening of the scope of traditional music research in stressing the role of the "music user" besides the music. Dealing with music, in this view, is a generic term that encompasses traditional musical behaviours - such as listening, performing, improvising and composing - as well as more general perceptual and behavioural categories (Reybrouck 1999, 2006a). All these categories can be [396] defined in a broader sense as a continuous process of sense-making that is grounded in our biology and our possibilities for adaptive control, and which can be typically described in ecological terms of coping and interacting with the sonic world.

The claims are challenging: they bring about a whole research program that argues for a kind of continuity between lower level sensory processing and higher-order cognitive elaboration. Major topics are the biological foundations of musical epistemology, the concept of adaptation and adaptive control, the role of interaction with the environment and the concept of experience.

\section{Dealing with music: towards an operational approach}

Musicology as a discipline has many topics of research. There are, in fact, prevailing paradigms such as historical research, music analysis and performance studies. On the other hand, new paradigms are evolving which 
challenge these traditional approaches by focussing on four major claims: (i) music as a sounding art, (ii) the process of dealing with music, (iii) the role of the musical experience and (iv) the process of sense-making while dealing with the sounding music. As such, there is a major turn in contemporary musicological research which argues for the broadening of the field from a "structural approach" to music — with a major emphasis on the delimitation of musical units and their interrelations - to a "processual approach" that also takes into account the "musical experience" (see Blacking 1955, Määttänen 1993, Reybrouck 2004, Westerlund 2002). Dealing with music, in this view, is a processual experience which is related to the definition of music as a "sounding" and "temporal" art. Hence the importance of the listening experience which is both sensory-driven and time-consuming. Listening, moreover, can be defined in ecological terms as "coping with the sounds", encompassing several levels of processing such as the perceptual, the computational/representational and the behavioural one (for an elaboration of the terms, see below). All these levels can be treated in isolation but they can be integrated in a more encompassing framework as well. As such, it is appealing to argue for an "operational" description of the major moments of dealing with music with at least two major claims: (i) the definition of music should be broadened from a rather restricted and limited category — the classical Western art music - to a more encompassing definition of music as a subset of the sonic environment, and (ii) the process of dealing with music should be approached from the positions of cybernetics and systems theory (Reybrouck 2005a, 2006b, c). The latter, especially, provide a useful "operational" terminology for describing the multiple interactions of an organism with its environment, relying on some very basic functions such as perceptual input, internal processing, effector output and feedback. 
The major moments of this interaction are exemplified in the "cybernetic" concept of a control system (see figure 1). Cybernetics, as a whole, is a unifying discipline

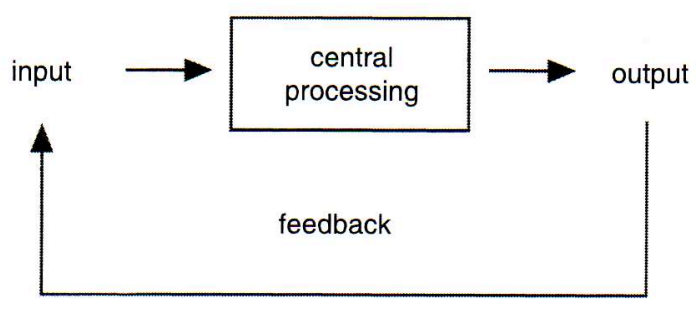

Figure 1. The basic schema of a control system

that brings togetheroncepts as different as the flow of information, control by feedback, adaptation, learning and self-organisation (see Bateson 1978 [1973], 1985, Brier 1999; Cariani 2003). It has reintroduced the role of the observer into science, and has stressed the major role of subjectivity as well. This has been emphasised particularly in "second order cybernetics", which typically conceives of the observer as a participant and as part of the observed system (see Luhmann 1995, 1990, Maturana and Varela 1980, Pask 1961a, b, 1992, von Foerster 1974, 1984). There is, in fact, a lot of freedom in the way observers construct their knowledge as the outcome of their interactions with the environmental world.

Dealing with music, accordingly, can be considered as a kind of "knowledge acquisition". It allows us to conceive of music in epistemological terms and to conceive of listeners as observers who construct and organise their knowledge and bring with them their observational tools (Maturana 1978: 28-29). The central point in this approach is the role of subjectivity and the way it influences 
our reactions to the environment. Living organisms, in fact, behave as subjects that respond to "signs" and not to "causal stimuli". This is a major claim of semiotic functioning that stresses the emancipation from mere causality and time-bound reactivity.

The latter has been advocated most typically by the pioneers of Russian objective experimental psychology in what they presented as reflex theories (Bechterev 1933[1917], Kornilov 1930, Pavlov 1926). Both Kornilov's reactology - which held the view that an organism is nothing but a bundle of responses to the environment - and Bechterew's reflexology — which studied reflex responses, especially as they affect behaviour-were major exponents of a naturalistic and mechanistic view on the relation between subjective experience and the material world. Both approaches also tried to offer a very needed alternative for mere idealistic psychology. They have proven, however, to be somewhat inadequate in being too behavioural and too reductionistic in their methodology. Reactive activity, e.g., involves a direct coupling between sensory input and resulting effects, based on a "historyless transfer function" of a particular automatism (Meystel 1998). Such a mechanism, however, seems to be inadequate for the explanation of goal-directed behaviour with deliberate planning.

Arguing on these lines it is obvious to question also the role of direct perception. This conception of the perceptual process - as elaborated in [398] ecological psychology (Gibson 1966, 1979, 1982)—holds that perception is possible without the mind intervening in the process. It involves presentational immediacy of the sensory stimuli and launches immediate reactions to the solicitations of the environment, proceeding mainly in real-time. There is a lot of empirical support in favour of this claim, yet it is possible to go beyond the constraints of mere reactivity and to put intermediate variables 
between the sensory stimuli and the reactions which are triggered by these stimuli (Paillard 1994, Reybrouck 2001b).

The position I hold is a biosemiotic and ecosemiotic one. Rather than relying on wired-in circuitry with well-defined reactions to well-defined stimuli, I argue for the introduction of mechanisms of sense-making and epistemic autonomy, as music users do not merely react to sounds, but to sounds as signs which are the outcome of current and previous epistemic interactions with the sounding world (Reybrouck 1999, 2005a). Music knowledge, in this view, is to be "constructed" and "acquired" rather than being merely "innate" and "wired-in". The mechanisms of knowledge construction, however, are not totally autonomous: there are perceptual, ecological and psychophysiological constraints which function as filters with respect to the information that listeners can actually pick up and process.

As such, we should consider the biological bases of musical epistemology (Reybrouck 2001a) with a corresponding tension between "nature" and "nurture"-referring respectively to the neurobiological claims of wired-in circuitry (innate and natural mechanisms) for perceptual information pickup - as against the learned mechanisms for information processing and sense-making. The claims may seem to be diverging at first glance, but they are complementary to a great extent. To quote Damasio:

"...as we develop from infancy to adulthood, the design of brain circuitries that represent our evolving body and its interaction with the world seems to depend on the activities in which the organism engages, and on the action of innate bioregulatory circuitries, as the latter react to such activities. This account underscores the inadequacy of conceiving brain, behavior, and mind in terms of nature versus nurture, or genes versus experience. Neither our brains nor our 
minds are tabulae rasae when we are born. Yet neither are they fully determined genetically. The genetic shadow looms large but is not complete." (1994: 111)

\section{Musical sense-making and the concept of code}

Understanding music is a multifaceted problem. There is no unambiguous answer to "what" listeners hear and "how" they hear. Much depends on attentional strategies and strategies of sense-making which may differ considerably between listeners. There are, however, basic mechanisms of sensemaking which are general across ages and cultures and which rely on levels of processing that are grounded in our biology (see Drake \& Bertrand 2003, for an overview). This is basically the "nature" side of the nature/nurture debate which has coloured musical discussions for decades. It is arguable that at least some mechanisms of musical sense-making rely on genetics rather than on culture. Yet there is the related question whether some reactions to music can spread [399] across the earth and become universals without genetic basis. As such, it may be interesting to look for mechanisms of "coding" and "decoding" which are so general that they are accessible to common music users all over the world.

These "universal" claims challenge that music research which has been rather narrowly focussed on the canon of classical Western music - the common practice tradition - with as paradigm a very particular way of concert culture where listeners are taught to listen "silently and respectfully" with a minimum of bodily movement or emotional expression (Cook 1998, Frith 1996, Small 1999). This listening habitus is typical of certain classical music traditionssuch as the Western and the Hindustani "classical" music - with an emphasis on stillness, focussed attention and inner withdrawal. Anthropological studies (Becker 2001), however, reveal other patterns of dealing with music, to mention 
only the role of social interactions and dialogical and situational forms of musical expression and emotion.

What I argue for, therefore, is a broadening of the definition of music from a restricted body of musical works to an approach which is both transcultural and transhistorical-from "music" to "musics" of the world — and which relies on psychophysical and neurobiological commonalities that are typical hallmarks of Homo Sapiens as one of the major developments of hominid phylogenetic evolution. Dealing with music, in this view, can be considered in terms of basic coding and decoding mechanisms which can be approached from different perspectives.

\subsection{Universals of perception, cognition and emotion}

Are there universals of music perception and cognition? Are there universals of musical emotion as well? Can we conceive of perception and cognition as separate faculties or should we rely on combined cognitive-perceptual activity of the brain in creating the experienced real world (Jerison 2000)?

The major contributions in cognitive musicology have focussed mainly on cognitive aspects of dealing with music. Musical emotions have been introduced only recently as a research topic with sufficient scientific relevance (Juslin \& Sloboda 2001b; Peretz 2001). Emotions, in fact, are difficult to study adequately, but the same holds true also for the idiosyncrasies of individual sense-making that rely on perceptual processing and cognitive functioning. A major question, therefore, is related to the "universal" claims of our reactions to music: can we rely on cross-cultural generalities or must we conceive of particulars that are embedded in cultural and historical contextual settings? 
Should we conceive of the primacy of the self-contained "individual" or must we take into account also the "supra-individual" which extends beyond the body and the mind of the single individual (Becker 2001)?

The answer is not clear. There is empirical evidence for both universals and specifics in the process of dealing with music. The problem, further, is exemplary of the tension between two positions in science: those that stress the "general" laws and instances as against those that stress the "cases" and [400] "interpretations" (Becker 1983, Geertz 1983). The search for universals in human functioning, however, has been controversial up to now. There are universals of language (Chomsky 1965, Greenberg 1963, Pinker 1994), human universals in general (Brown 1991, Murdock 1945, Pinker 2002,) and even universals which are related to the mechanisms of arousal and primary emotions (Becker 2001).

Conceiving of universals in music, however, is less obvious. The strongest criticisms have been provided by ethnomusicologists who have stressed again and again the importance of cultural relativism (Becker 2001). It is necessary, therefore, to broaden the scope of research and to relate the process of musical sense-making to the search for universals in general.

A starting point is the experimental principle from developmental research that allows us to tease apart the processes that appear to be innate or hard-wired from those that develop with maturation and acculturation (Drake 2003). The procedure is quite simple: if young infants, children and adult musicians display similar modes of functioning on particular task, then it can be concluded that the process is innate or at least functional at an early age (Drake and Bertrand 2003: 22). The same principle can be applied to the study of children (developmental research) and intercultural research (comparative research) with the aim to 
answer the question of the true "universal" nature of psychological processes in general.

A major contribution to these problems has already been made in the field of evolutionary linguistics. In a continuous attempt to motivate the emergence of "linguistic universals", there has been a first reduction to three major categories: phonological, syntactic and semantic universals. The major efforts of the endeavour, however, have focussed traditionally on "phonetic" and "syntactic" rules and principles. Most languages, in fact, have vocabularies of words whose articulatory and acoustic definition is mediated by a phonological system (Liberman 1975, for a critical discussion see Port and Leary 2005). The majority of the contributions, however, has dealt with syntax rather than with phonetics. The Chomskian tradition in linguistics is illustrative of this approach: it tries to find the set of abstract grammatical principles that underlie all human languages, a kind of "universal grammar" that relies on the assumption of universals as innate features of a "language faculty". According to Chomsky, humans are born with an innate knowledge of language - the language facultyas a biologically autonomous system in the brain that has an initial state which is genetically determined (Chomsky 1965: 13, see also Hauser et al. 2002). The basic tenet in this approach is the innateness of linguistic ability and the belief that the genetic base for language came about as the result of Darwinian evolution. The question, however, is still subject of discussion.

The search for linguistics universals has played a less important role in semantics (van Rooij, 2005). The only exception is the discussion of "semantic universals" which are related to colour and kinship terms (Berlin and Kay 1969, Leech 1974). The prototypical example of colour terms seems to argue for semantic universals that are induced by perceptual universals with pan-human [401] perceptual processes constraining lexical semantics. There exist eleven 
basic colour terms — black, white, red, green, blue, yellow, brown, purple, pink, orange and grey—which may correspond to a universal pattern of perceptual salience that determines an apparent lexical salience of certain focal colours. Other examples are the kinship relations (father-of, mother-of, husband-of, wifeof, son-of, daughter-of, brother-of, sister-of, identical-to) and the case of pronouns that are used in talking to someone about ourselves (singular pronouns - "I" and "you"-, plural pronouns-"we").

Besides this search for semantic "universals", there is another approach, which has focussed on semantic "primes". If languages have irreducible semantic cores, it must be possible to reduce them to the smallest and most versatile set of words which are, in a way, indefinable. These are semantic primes which are linguistic expressions whose meaning cannot be paraphrased in any simpler terms and which have a lexical equivalent in all existing languages (Goddard 2002, see also Wierzbicka 1996).

The question, now, is how to relate these universals to the realm of music? Here, also, there has been a major focus on "syntax" and "structure "with a corresponding neglect of "semantics". The question, therefore, remains as to the desirability and viability of musical semantic universals with as major questions: what do listeners hear? what kind of distinctions do they make? what kind of sense-making do they rely on? and are there any causal relations between the music as a stimulus and the listener's response?

The answer is complicated by the twofold nature of music as a temporal and sounding stimulus. Music, in this view, is not to be conceived as a symbolic stimulus with semantic meaning which can be dealt with out-of-time, but as a time-consuming and sounding processual event which impinges upon our sensory and perceptual apparatus. As such, its primary meaning is not lexical 
but experiential (Reybrouck 2005a, b). Musical semantics, therefore, is in search not only of the "lexicosemantic" - conceived almost exclusively in terms of referential semantics which is couched in the form of abstract and emotional neutral cognitive representations - , but also of the "experiential" dimension of meaning, which, in turn, is somewhat related to the "affective" dimension of meaning. Affective semantics, further, carries the mark of the ties that connect humans with their environment. It has been neglected still more than the lexicosemantic dimension of language (Molino 2000).

The claims have already received some empirical support. There is, first, evidence from evolutionary perspective with as typical example a class of primate vocalisations - called referential emotive vocalisations - which embrace a type of call that serves an on-line, emotive response to some object in the environment. These vocalisations have a dual acoustic nature in having both a referential and emotive meaning (Frayer and Nicolay 2000). Additional empirical grounding comes from "physiological reactions" that have shown to be correlates of listening to music (Krumhans1, 1997; Scherer \& Zentner, 2001; Peretz, 2001). Some of them are physiological constants, such as the induction or modification of arousal, which can be defined in its most narrow sense as a stimulation of the autonomic nervous system. They play a major role in [402] numerous studies of music and emotion, but many questions are still open with regard to their affective and interpretative components.

\subsection{Universals in music: do they exist?}

The mere existence of music is universal as every culture which is known today has music in some form. There is, however, no agreement as to the nature of this universal claim: is music a cultural-social universal or is it grounded in our 
biology? The stance of a famous ethnomusicologist as Blacking is exemplary of the case. He commonly admitted that music-making is a fundamental and universal attribute of the human species, but he warned against "universals" in musical meaning, stating that the conventions of musical systems and people's emotional response to them are cultural constructs. Even within well-defined cultures, there are so many idiosyncrasies and subjectivities that the mere claim of universal meaning in music seems problematic. Yet, he accepted the existence of psychophysical commonalities between disparate tonal systems, as well as the major role of relatively unchanging biological processes of aural perception in discovering patterns of sound :

"... it is clear that the creation and performance of most music is generated first and foremost by the human capacity to discover patterns of sound and to identify them on subsequent occasions. Without biological processes of aural perception, and without cultural agreement among at least some human beings on what is perceived, there can be neither music, nor musical communication." (Blacking, 1973: 9, see also Balkwill 1997)

This quote foreshadows the current alignment between music and biology. It is exemplary of a paradigm shift in thinking of music in terms of universals, which was initiated by the 1970s - two journals published a special issue on the topic: Ethnomusicology $(1971,15,3)$ and The World of Music (1977, 19, 1/2), see Nettl, 2000). More recently, the topic of universals has received renewed attention in "musicological" research (see Brunner 1998, Kon 1998, Marconi 1998, Miereanu and Hascher 1998; Normet 1998, Padilla 1998). But, above all, there is the new field of biomusicology (see Wallin 1991, Wallin et al. 2000) which aims at resuscitating the concept of musical universals, in taking full advantage of current developments in Darwinian anthropology (Durham 1991), evolutionary psychology (Barkow et al. 1992) and gene-culture coevolutionary 
theory (Feldman \& Laland 1996, Lumsden and Wilson 1981). It addresses the basic question of the origins of music, and comprises three main branches: evolutionary musicology, neuromusicology and comparative musicology. To quote Brown et al.:

"Evolutionary musicology deals with the evolutionary origins of music, both in terms of a comparative approach to vocal communication in animals and in terms of an evolutionary psychological approach to the emergence of music in the hominid line. Neuromusicology deals with the nature and evolution of the neural and cognitive mechanisms involved in musical production and perception, as well as with ontogenetic development of musical capacity and [403] musical behavior from the fetal stage through to old age. Comparative musicology deals with the diverse functional roles and uses of music in all human culture, including the contexts and contents of musical rituals, the advantages and costs of music making, and the comparative features of musical systems, forms, and performance style throughout the world." $(2000,6)$.

There is need of additional foundational and methodological research in order to give this new research domain its full academic flavour, but the interdisciplinary approach is likely to be fruitful as a starting point. The combined contributions from ethnomusicology, biomusicology, evolutionary musicology, neuromusicology, cognitive musicology, comparative musicology and zoomusicology are likely to provide a lot of insights that go beyond approaches that have been rather intuitive up to now. Some questions, however, remain unresolved. One of them is the tension between culture and biology.

The biological position argues for wired-in mechanisms of reactivity to sounds or music, the cultural position argues for variables that are the outcome of immersion in a culture. Rather than thinking in terms of a dichotomy, however, 
it is fruitful to consider the dependency between both variables (see Wallin 1991: 6). Listeners, in fact, are biological organisms which are immersed in a culture. But even culture did not evolve in a vacuum. Both culture and music are born out of man's "animal characteristics" which are rooted in the biology of perception and cognition, and this may be universal to a great extent (Goldschmidt 1959). Even at the level of acquired habits and learned responses, there seems to be a lot of commonality. It allows us to conceive of universals in music which exist beneath the surface of cultural variation and mere subjectivity (Balkwill 1997).

It may be fruitful, in this context, to consider the contributions from neurobiology and ethnomusicological research. As Nettl puts it: "If ethnomusicological involvement has some justification, it concerns the interface among three areas of concern: cultural universals, musical universals specifically, and the origins of music." (Nettl 2000: 464). Musical universals, especially, can be helpful in theorising about the origins of music: to the extent that surface structures - musical features - are showing similarities which correspond to concepts provided by evolutionary theories, it can be stated that the universal and the biological coincide (Imberty 2004: 450).

There are, further, three major topics of concern: (i) the fact that music is a widespread phenomenon all over the world, (ii) the neurophysiological substrates that underlie common responses to sounding music and (iii) the observation that there are musical traits which are common among humans regardless of origin and culture. Additional issues include the question whether music is to be dealt with at a "structural" or an "experiential level" (see Reybrouck 2005a, b, 2006a) and the role the body plays in this experience. It really makes a distinction if we conceive of music at a level with surface 
features that are describable in an objective way — structural level — as against music as a process which is enacted in a social setting.

As to the first topic - music as a widespread phenomenon all over the world-, it is possible to conceive of music as a universal phenomenon with adaptive [404] power. According to Miller (2000, see also Trehub 2003), music exemplifies many of the classic criteria for complex human adaptation: (i) no culture in any period of recorded history has been without music (universality); (ii) the development of musical abilities is orderly; (iii) the ability is widespread in the sense that almost every normal adult can appreciate music and carry a tune (basic perceptual and performing skills); (iv) adults can recognise thousands of melodies, implying specialised memory; (v) special-purpose cortical mechanisms are involved; (vi) there are analogues in the signals of other species such as songbirds, gibbons, and whales, raising the possibility of convergent evolution; and (vii) music can evoke strong emotions which implies receptive as well as productive adaptation.

As to the second topic - the neurophysiological substrates of music perception-, there are common biological characteristics which all human beings share. Some perceptual activity is even common to various species beyond the human species and there is good reason to assume that in most vital features the world as experienced is stable among species (Jerison 2000: 187). The same probably holds true for dealing with music. There is, however, great scepticism among ethnomusicologists who conceive of universals of perception as "smacking too much of biological determinism, and ... of denying the importance of historical forces and cultural traditions in explaining the properties of musical systems and musical behavior". (Brown et al. 2000:14) A possible solution to this reluctance could be the biocultural view which argues for a balance between genetic or biological constraints on the one hand, and 
historical contingencies on the other. Musical universals, in this view, place all humankind on equal ground and focus on the unity that underlies the great diversity present in the world's musical systems, attributing this unity to neural constraints underlying musical processing (Brown 2000).

As such, much can be learned from the study of perceptual processing dispositions which are likely to be genetically prewired. A technique for studying them stems from human infant studies: if substantial adult-infant similarities are evident in the perception of music, one could argue that at least some aspects of music processing have a biological basis. It means further that perception of music is inherently biased rather than unbiased. The musics of the world, in this view, have capitalised on these biases or universals of auditory pattern processing, which should mean that music from different cultures could be expected to share some fundamental properties (Trehub 2000: 428).

A somewhat related field of research is the topic of infant-directed speech as used by caregivers over the world. Most of them enhance their vocal messages to prelinguistic infants by making them more musical than usual. This is done by several techniques: using simple but distinctive pitch contours but articulating words poorly; raising or lowering the pitch level and expanding or reducing pitch contours; slowing tempo and making the utterances more rhythmic and repetitive (Trehub 2000: 437).

The observation, thirdly, that there are musical traits which are common among humans, regardless of origin and culture, is generally accepted by musicologists though there is no absolute agreement on what they are. One should call to mind, however, that universals need not necessarily apply to all existing music (Nettl 2000). In an attempt to generalise as much as possible, it should be [405] recommended to focus not exclusively on "great" music but also to embrace all 
kinds of primitive and popular music. As Molino puts it: "our conception of music, based on the production, perception, and theory of "great" European classical music, distances ourselves irremediably from the anthropological foundations of human music in general." (2000: 170) It surely makes sense to study some well-established musical notions with quasi-universal charactersuch as scales, key notes, bars, melody, harmony and tones as opposed to noises (Mâche 2000) —, but much of their relevance is questionable when applied to non-Western musical cultures.

As such, it is arguable to list up common features of music all over the world, or, as Arom puts it, to conceive of "anthropomusicology" as "the scientific discipline that would deal with the suite of human musical properties as they are manifested in the ensemble of known musics."(2000: 27) In an attempt to determine such a minimal set of criteria, he provides a provisional list of universals or quasi-universals which are specific to music: (i) intentionality or an act of intentional construction, (ii) a formal process which detaches the music from the sound environment and which gives the musical substance an internal articulation in terms of proportions (formalisation of time through temporal ratios, periodicity and the principle of symmetry), (iii) a set of contrastive pitches (musical scales), and - if the music involves more than one individual(iv) modes of co-ordination between them (ordered and simultaneous interactions).

Another contribution considers two universal features to account for a large part of what music is at the structural level: "pitch blending" and "isometric rhythms". The first refers to the simultaneity of pitched sounds. In opposition to speech, which proceeds by a successive alternation of parts, music has the intrinsic capacity for promoting co-operative group performance and interpersonal harmonisation with pitches sounding together at the same moment 
(Frayer and Nicolay 2000). The feature of isometric rhythm, on the other hand, involves the level of temporal organisation that is regular and periodical and which corresponds to the regular points in the music to which one could tap one's foot (Cross 2003).

Other universal features could be listed, but even if the list should be exhaustive, the question remains as to what is innate and what is acquired. As Huron puts is:

"Music is now deeply embedded in a cultural/historical context where human musical memories span centuries, and the fashion cycle is a significant engine of change. Music is now part of a Lamarckian system where acquired characteristics are transmitted in Dawkinsean 'meme pool' rather than in Mendelian 'gene pool'." (2003: 73, see also Dawkins 1976)

\subsection{Primary and secondary code}

The problem of musical universals is directly related to the origins of music. It calls forth evolutionary claims and the related question whether music has some [405] adaptive function both at the phylogenetic and ontogenetic level of human beings as biological organisms. A central issue in this discussion is the tension between human's innate reactivity to stimuli in general and those reactions which are acquired through ontogenetical development. Or put in other terms: is musical sense-making coded in our genetic programmes with reactions which rely on pre-wired and innate programmes or should we conceive of music as something which calls forth higher functions of the brain? And can we conceive of musical sense-making in terms of a dichotomy (innate/acquired) or should we think in terms of complementarity between distinct levels of processing? There is, in fact, a lot of evidence that points towards a hybrid 
position, with music acting as a stimulus that induces primary reactions which can be filtered by the cognitive apparatus as well.

The problem is further complicated by the critical distinction between perceptual "development"-which is merely the outcome of maturation and aging - and perceptual "learning". It is necessary, therefore, to tease apart those changes that are the outcome of experience from those that are the outcome of the normal growth of individuals.

An interesting starting point here is the theoretical work on codes and code acquisition in general. There is, in fact, a distinction between quasi-automated wired-in reactivity and those reactions that are the outcome of at least some learning history. As such, it is instructive to observe human behaviour in general and to examine the way it can be classified in different cultures all over the world. An important representative of this approach was Murdock (1945) who introduced a classification of cultural-social universals in anthropology with three major categories: (i) universals which correspond to primary, genetically coded (instinctive) impulsion, (ii) universals which correspond to acquired habits and which are rooted in fundamental bio-psychical demands and (iii) universals which correspond to cultural habits with only very thin links to the conditions of the secondary level. Murdock did not totally deny the existence of an "animal level" of culture and society, but these animal characteristics can serve only the most general conditions for culture and society. All attempts which go further in explaining should be considered as mere reductionism (see also Goldschmidt 1959).

Murdock's view is somewhat related to Bystrina's concept of “codes", which, in his view, are defined as relatively invariant systems of rules that regulate the processing of information. A distinction can be drawn between three layers of 
processing: the phylogenetically earlier primary (or hypolinguistic) codes - the genetic code, the intraorganic and perception codes - are of an innate nature; superimposed on them are secondary codes (linguistic or sign codes) which are the result of a learning process; they provide the basis for tertiary (hyperlinguistic or text codes) - also called cultural codes - which operate at a level above the secondary codes. It is assumed, further, that the invariants of tertiary codes have developed as imprintings in especially sensitive phases of the evolution of man (see also Jiranek, 1998).

[407] There is much of value in these ideas, even if some of them are too general to be operational. To quote Wallin:

"There are certainly genetically coded impulses ..., but the most forceful of them are not reserved for man alone: to satisfy sexual needs, hunger, thirst, etc. Language and music, two very human abilities, do not correspond to impulses or instincts. They are, as such, not coded into the genetic program. Into the genetic code is inserted information or constraints concerning how, in situations of vital emergency, to mobilise the most effective displays in order to attract or detract other organisms; among these constraints are included optimal functional pathways between mechanisms, through which signals and signs can be produced.“(1991: 8-9)

The genetically programmed codes are fast and efficient. They are, however, restricted in their scope and functions. As Barbieri puts it:

"The interpretation process that we observe in many animals can easily be understood as an evolution of their signal processing systems. It is likely that the most primitive reactions were heavily determined by genes, but the number of hard-wired responses could not increase indefinitely, and animals became more 
and more dependent on processes of learning in order to increase their behavioral repertoire." (2005: 124)

Innate reactions, further, are perceptually primitive in a radical sense. Most animals and men, according to Cariani, have neural coding strategies that are used in representing and processing sensory information. They encompass basic body plans, sensory organs and neural representations that are roughly similar (Cariani 1998). There is, in other words, a whole domain of "sensory coding" which can be studied in a straightforward way.

The domain of sensory or perceptual systems is prototypical. It is one of the rare domains which allow a kind of low-level automatic and elementalist approach to the processing of information with mapping functions between perceptual input and behavioural reactions that suggest some kind of causal relationships. But even at this level of processing, there should be made an effort to go beyond the computation of correlation coefficients between a single independent variable and a single dependent variable as perceptual phenomena have multidimensional rather than unidimensional determinants (Uttal 1998: 200). Or put in other terms: the relation between perceptual sense-making and sensory stimulation is not as causal and linear as would be assumed, even at the level of sensory processing.

\subsection{The concept of coding}

The concepts of code and coding entail a lot of ambiguity. They have been used in semiotics and communication theory, in cryptographics, in neurophysiology and sensory physiology as well as in genetics. The word coding, however, has a 
relatively constant meaning which is related to the nature of "representation". To quote Uttal:

“... how do signals or symbols from one universe of discourse represent patterns of information from another. The major theoretical notion that underlies coding theory is that there are invariants of organization, patterns, or meaning, which [408] can be conveyed from sources to destination even though represented by different symbols and in different kinds of physical energies in the communication process. "(1973: 207) And further: "What, then, is a formal definition of a code? We may define a code as a set of symbols that can be used to represent message concepts and meanings (patterns of organization) and the set of rules that governs the selection and use of these symbols." (1973: 208)

Coding theory resolves some problems of psychobiological equivalence. It states that any dimension is capable of representing any other dimension. Rather than starting from dimensional isomorphism between stimulus and neural representation, it involves a system of codes or cues which are able to symbolically represent — rather than geometrically replicate — external stimulus patterns (Uttal 1978: 26). The representation of the amplitude of a stimulus by a train of nerve impulses is a typical example.

The key problem of coding theory, however, is the relation between a stimulus with a certain physical intensity, its neural coding through neural fluctuation and some perceived sensory dimension (the subjective experience) (Uttal, 1978: 416). Two questions should be answered here: which are the relevant neural parameters - properties of neurophysiological signals - that vary as a function of the stimulus variables and which are the common sensory dimensions? 
Many properties of signals can function as symbols for the dimensions of perceptual experience: place of activation, number of activated units, neural event amplitude and temporal pattern of the activated units. All of them are candidate neural codes which can be directly established by neurophysiological research. They do, however, not necessarily bear any resemblance to "perceptual significance". In order to be true codes some additional criteria must be met: they must vary as a function of some stimulus variable, they must be interpreted by some subsequent mechanism, they must be both necessary and sufficient for the concomitant variation of some behavioural experience and they must actually become the equivalent, at some stage, of a mental process (Uttal 1973: 212). As such, there is a distinction between what is merely concomitant and what is truly relevant.

The common sensory dimensions, on the other hand, can be considered from their perceptual aspects rather than from the dimensions of the physical stimulus itself. Such a set of discriminable dimensions is modality independent which means that it can be used to describe patterns in any sensory modality whatever (Uttal 1978: 416). Examples of such coding factors are "perceived quantity" or sensed intensity or magnitude of a physical stimulus, "perceived quality" or the kind or quality of a sensory experience, and "temporal discriminations" such as relative temporal order - which of two different stimuli came first?-, temporal acuity - ability to distinguish two identical stimulus events which are sequential in time as separate events - and duration or interval — ability to replicate the sustained duration of an event or interval between two events (Uttal 1978: 418).

\section{[408] 3.5 Coding and representation}


Coding theory is related to two major problems of psychobiological equivalence: the problem of the mind-body or - in a more reduced sense - the mind-brain relationship and the particular ways in which mental processes are encoded and represented. Its major claims are that the nervous system provides the immediate, necessary and sufficient mechanisms for the embodiment of all mental processes and that mental processes are reducible to the function, arrangement, and interaction of neurones as the constituent building blocks of the nervous system (Uttal 1978: 26 and 355).

Coding theory, further, argues against isomorphically oriented theories that claim a kind of dimensional isomorphism or similarity between stimulus and representation. It also rejects the need of linear relationships between neural coding dimensions and psychophysical dimensions. It only claims an equivalence of maintained information from the neural states to the psychological state (Uttal 1978: 68).

Real coding, in this view, means that any dimension is capable of representing any other dimension. It involves a system of codes or cues which are able to symbolically represent external stimulus patterns (Uttal 1978: 26). As such, it is not sufficient to discuss merely the physical stimulus dimensions. The latter can be very quickly re-encoded into entirely different stimulus dimensions, even within the sensory receptor itself. It is more fruitful, therefore, to consider the codes that are situated at least at the level of conversion of physical energy into neural energy. This is the "transductive process" with the concept of "neural code" as a prototypical example. It has been proposed as the outcome of the observation that single neurone responses vary concomitantly with some variant in a physical stimulus dimension (Uttal 1973: 212). 
The fundamental problem of a theory of sensory coding and neural representation, further, is the association between percepts, experience and thought on the one hand, and the candidate neural dimensions on the other hand (Uttal 1978: 430). It entails a kind of neural reductionism in focussing rather narrowly on the relationship between single cell responses and psychological functions. Yet this has proven to be valuable in the domain of sensory or perceptual systems - especially in the visual domain (dark adaptation, the Mach band, the blind spot, colour sensitivity, and a number of other phenomena (Uttal 1998, XI), where perceptual phenomena seem to reflect neuronal transformations produced by the early or peripheral portions of the sensory pathways.

Sensory coding is characterised by its relative simplicity: there is an initial isomorphism of stimulus and receptor response, and a primarily unidirectional flow of information (Uttal 1978: 356). But even here, the problem is much more complex and multifaceted than "the" sensory coding problem. The latter has emphasised traditionally the single aspect of singular determination of the functional relationships between stimulus intensity and nerve impulse frequency. As is obvious from psychophysical research, however, there is no simple psychophysical law that determines the relationship between perceived [410] magnitude and stimulus dimensions. Many other dimensions, such as quality, temporal and spatial parameters, must be encoded by neural signals as well (Uttal 1978: 415).

A central question, therefore, is how this "representation" maps in some direct way onto the domain of "psychological responses". It represents the general process by which neural signals or responses come to be the physical equivalent of mental processes (Uttal 1978: 357). As such, it is one of the major research issues of modern psychobiology: "The fundamental problem of representation is 
to determine how discrete neural processes can serve as the transactional equivalents of molar psychological processes. "(Uttal 1978: 24)

"Sensory coding", in this view, is a rather poor model of cognitive coding theory, in the sense that the central cognitive or symbolic coding moves away from straightforward mappable representations. To quote Uttal once more:

"The central symbolic processes ... allow considerable "patching" to be done to the relatively poor sensory information that does make its way to the intrinsic areas. Holes may be filled in, clues interpreted, past experience introduced, and judgments made about relationships that differ considerably from the simple geometric or temporal characteristics of the original stimulus. The criteria of excellence of integrative mechanisms are, therefore, based on the richness of the mixture of information and the deviation from, rather than fidelity to, simple reproduction of the input stimulus patterns." (Uttal, 1978: 414-415)

As such, one can question the claims of psychophysics as a major attempt to provide reliable correlations between the sensory levels of stimuli and their perceptual processing. It is interesting, therefore, to consider additional mechanisms of processing and sense-making that go beyond mere linear response functions of given receptors.

\section{Principles of perceptual organisation: steps and levels of processing}

Dealing with music is a psychological process of "coping" with the sounds. There are, however, different levels of sense-making with a major distinction between low level, quasi-automatic reactivity to typical stimuli, as against cognitive processing that entails some intermediate variables between the 
stimuli and the reactions to these stimuli. The distinction is critical, both in terms of processing efforts and cognitive economy_information "pickup" as against information "processing"-, and in terms of sense-making. There is, in fact, a long-lasting debate on the causal relation between stimulus and response, with the related issue of direct perception and naturalistic approaches to semiotics and sense-making in general (see Leman 1999). There are surely advantages in recognising the consistency of cause and effect. It allows us to use invariant and consistent sensory responses as guides to objects or events, which, in turn, provides adaptive power for coping with our environment.

\section{[411] 4.1 Levels of processing}

A central question in the perceptual processing of music is the transition from sensation to perception. It is an old topic in the psychology of perception in general. "Sensation" is usually defined as the conscious response to the stimulation of a sense organ or nerve receptor, but this definition does not account for the totality of the contents of consciousness in an act of perception, which involves selection among sensations, combination, organisation and sometimes even supplementations from imagination (Lee 1938: 24-25). Perception, further, is a rather complex phenomenon. According to Uttal, it is the "... relatively immediate, intrapersonal, mental [experience] evoked as a partial, but not exclusive, result of impinging multidimensional stimuli, as modulated by the transforms imposed by the neural communication system, previous experience, and contextual reasonableness. Each percept is the conscious end product of both simple computational transformations and more complex constructionist interpretations. However, the underlying neural and symbolic processes are not part of the observer's awareness. “(Uttal 1981a: 14) Perception, in this view, always takes place against the background of previous 
experiences and its study should be conducted in terms of processing of information.

Major efforts have been undertaken in order to find linear and causal relations between stimuli and responses with the field of "psychophysics" as a prototypical example. In a somewhat broader sense, this was also the aim of early "psychobiological research": to find out the relation between mental processes and their underlying physiological processing mechanisms. This "body-mind relationship", however, has proven to be less predictable than was hoped for. The biological and physiological roots of perceptual processing may be interesting as a starting point, but there are so many other mechanisms cognitive, affective, attentional, motivational - that interfere in the processing, that the early hope for unidimensional correlations has proven to been illusory. There is, further, a whole machinery of "transactional" processes between the listener and the music (see Mowbray and Rodger 1963 for perception as transaction between perceiver and environment, see Berne 1964 for the topic of transaction). As Deschênes puts it:

"If we appreciate a particular type of music, it is due neither to the music itself or to the musicians, but rather to the interaction going on between our mind content and body, the music, the musicians, the values carried by the music (social, moral, or otherwise), and the sensations we are looking for in the music, and to the correlation that we can create between this music and these sensations and perceptions. Music surely activates in a listener quantifiable percepts, but what is retained after any listening are the qualities that these awaken in the listener's consciousness during the listening process." (1991: 199)

As such, there seems to be a lot of subjectivity. Yet, there are universal processing mechanisms that go beyond the idiosyncrasies of individual and 
subjective reactions to the sound. As a rule this applies to the lower levels of processing — with the risk of psychobiological reductionism-, and the ecological levels of coping with the world. There are, however, lawful commonalities at higher levels of perceptual processing as well. This seems to [412] suggest that perception is not merely a primitive data-driven process which works independently of top-down influences. The Gestalt laws of perception are illustrative of this point (see Köhler 1947, Koffka 1935, Wertheimer 1923 for the seminal publications, and Bregman 1981, 1990, Leman 1999, Reybrouck 1997, for musical applications). According to Pomerantz (1986) there are no less than 114 Gestalt laws for object perception, suggesting that they can hardly be built into a primitive data-driven process. This sheer number simply calls forth higher levels of processing and information organisation, although some rules for recognising the natural world's regularities seem to be embodied in the hardware of our brains. It is interesting, therefore, to consider some of the basic mechanisms of perceptual organisation in general and, more specifically, the levels of perceptual processing.

According to Neisser (1967), there are at least three stages of processing: the preperceptual, perceptual and cognitive stage. Applied to music, this means that the level of conscious and active listening is preceded by a passive stage of filtering and feature-detection (Neisser 1967: 199, see also Seifert 1993: 180182): the passive mode is fast and less demanding as to processing efforts - it relies on wired-in programs and mechanisms - , the higher levels of processing, on the contrary, are more demanding and are not reducible to causal stimulusreaction chains.

It has been shown, moreover, that there are distinctive and successive stages in perception (Levine and Schefer 1981, see also Rosenberg and Adelstein 1993, Sekuler and Blake 1985). At first, there is a distal stimulus which corresponds to 
the actual object in the environment. It is the distant source of sensory information which corresponds to the energy emitted by or reflected from some object. Secondly, there is a proximal stimulus which is commonly defined as the pattern of energy that impinges on the sensory receptors. It is to this kind of stimuli that human beings have access when they interact with an environment rather than to the stimuli per se. Or put in other terms: observers depend most directly on proximal and not on distal stimuli in perceiving their environment. The act of perception, further, involves the transduction, transmission and processing of the stimuli. Transduction means the conversion of energy from one form to another as a result from the sensory action. It involves a number of steps, the first of which is the alteration of the chemical equilibrium of the receptor by the physical energy of the stimulus (Uttal 1973: 12). The transmission step is the transfer of information-bearing electropotentials propagated from peripheral portions of the nervous system to other more central portions. The processing process, further, is hypothesised to involve a judgement of which distal stimuli most likely caused the sensation, a kind of compromise between what is presented and what is selected to denote a systematic response tendency. It involves an act of "inference" which is commonly known as the perceptual hypothesis (see Krechevsky 1932a, b, c) and which results in the generation of an internal representation of the outside world: the percept. In order, however, to make a correct perceptual hypothesis the perceptual system must be presented with enough salient sensory information in a proximal stimulus. If this is the case, an appropriate internal model of the actual distal stimulus will be created. The last stage of perception, finally, is [413] action or reaction, which may consist of cognitive or motor responsesboth manifest and internalised - to the sensory input.

All this has implications for a genuine perceptual theory. In the main, it is not sufficient to explain perception in terms of distal stimuli or of separate senses. 
What is needed is a theory that does justice to the relation between "distal" and "proximal stimuli". In an unpublished paper Gibson (1961) provided an interesting attempt to classify the senses and the sensory inputs accordingly, together with some criticisms of the traditional approach to perception. The latter embrace the following remarks: the classical sensations are only poor guides to the description of the receptive process in general; the typical variables of stimulation, borrowed from physics, are oversimplified; and the relation between stimuli and their sources in the environment - the so-called "proximal" and "distal" stimuli-has never been worked out in detail. The channels of sense-perception, further, cannot be represented by any fixed list of mutually exclusive "senses".

What he argues for, on the contrary, is an overall picture of the receptive process as a whole with several categories and subcategories at different levels of the process: (i) the receptive system which can be excited and which can be split up into receptive elements that are connected to an afferent neurone, sensory surfaces that group together bundles of adjoining neurones, and sensory systems, which consist of a sensory surface with its neural connections and motor equipment for adjusting and exploring stimulation; (ii) the types of stimulus energy that can excite them, (iii) the environmental fields of potential stimulation which do not relate primarily to substantial and material things but rather to potential stimuli for the sense organs, (iv) the environmental sources of these fields of stimulation which comprise the environment that can be registered by the senses, and (v) the general sources of stimulation, which are inner and outer sources of variation of proximal stimulation, involving changes in the environment, the muscular actions of the body, sensory adjustment and exploration by the perceiver and moving in the world. 
The overall picture is challenging: it goes beyond the classical distinction between mutually exclusive modalities of senses and sense data as well as beyond the basic variables of stimulation such as intensity, frequency, duration, location and extension. Even the distinction between "proximal" and "distal" stimuli is insufficient as there are sources of stimulation at more than one level of perceptual analysis.

\subsection{Nativism and the wired-in circuitry}

Dealing with music relies on low levels of reactive behaviour and higher levels of cognitive processing. As such, there are several related questions: (i) what is the role of innate and wired-in circuitry? (ii) can music be processed automatically and at a preattentive level? (iii) can we conceive of musical competence as an innate faculty somewhat analogous to linguistic competence? (iv) are there brain substrates for music processing? (v) and what is the role of [414] emotion in music processing?

There are, first, information-processing mechanisms that are basic and innate and that rely on low-level neural architecture which functions as wired-in reactive circuitry. According to Damasio, they are designed to solve automatically the basic problems of life, such as finding sources of energy, incorporating and transforming energy, maintaining a chemical balance of the interior of the body, maintaining the organism's structure by repairing possible impairment and fending off external agents of threat. Most of these mechanisms are part of the regulatory homeostatic machinery that provides the innate and automatic equipment of life governance. At the bottom of this organisation are very simple responses such as approaching and withdrawing, or increases (arousal) and decreases in activity (calm or quiescence) (Damasio 2004: 31). 
Most of this reactive behaviour points into the direction of automatic processing beyond conscious and deliberate control. It involves a lot of biological regulation that engages evolutionary older and less developed structures of the brain such as the hypothalamus, brain stem and limbic system. Such a "primitive" processing mechanism, however, has considerable adaptive value: it provides the organisms with levels of elementary forms of decision making which rely on sets of neural circuits which do the deciding (Damasio 1994: 123127).

According to Damasio, there are at least four levels which precede the stage of conscious control: the level of metabolic processes, basic reflexes and the immune system; the level of behaviours which are associated with the notion of pleasure or pain (reward or punishment); the level of drives and motivationshunger, thirst, curiosity and exploration, play and sex-; and the level of emotions-proper (Damasio 2004: 34). The whole machinery, however, ensures an organism's survival. Based on innate strategies, it permeates the human brain from the start of life with knowledge regarding how to manage the organism, including both the running of life processes and the handling of external events. The mechanisms, however, are rather general. It is interesting, therefore, to look for similar ones which are related to the processing of music.

\subsection{Arousal, emotion and feeling}

There are two major ways of dealing with music: music can be considered as something which catches us and which induces several reactions which are beyond conscious control, or music can be processed in a conscious way that appeals to several higher functions of the brain. As such, it is possible to 
respond to musical sound patterns with two distinctive strategies of sensemaking: the acoustic and vehicle mode of perceiving and responding (Frayer and Nicolay 2000: 278) — see also the distinction between rhythmo-affective and representational semantics (Molino 2000). The first involves emotive meaning with particular sound patterns being able to convey emotional meanings; the second involves referential meaning, somewhat analogous to the lexicosemantic [415] dimension of language with arbitrary sound patterns as vehicles to convey symbolic meaning.

The acoustic mode of responding refers to the immediate "emotive aspect" of sound perception and production. It relies on the process of sentic modulation (see Clynes 1977), which is a general modulatory system that is involved in conveying and perceiving the intensity of emotive expression by means of three graded spectra: tempo modulation (slow-fast), amplitude modulation (soft-loud) and register selection (low pitch-high pitch), somewhat analogous to the wellknown rules of prosody which encompass our most basic idea about intonation. It refers to the local risings and fallings, quickening and slowing, and loudenings and softenings that are involved in expressively communicating meanings. The sentic modulation process appears to be invariant across modalities of expression - this is Clynes' "equivalence principle", which states that a sentic state may be expressed by any number of different output modalities in humans, such as speech, music, and gesture (Clynes 1977: 18, see Frayer and Nicolay 2000).

This sentic modulation, further, hints at an important aspect, namely how expressive qualities vary and change in a dynamic way. Emotional expressions are not homogeneous over time, and many of music's most expressive qualities relate to structural changes over time, somewhat analogous to the concept of prosodic contours (Frick 1985) — dynamic patterns of voice cues over time- 
which are found in vocal expressions (Juslin 2001a: 317). The same mechanism is to be found in the practices of caregivers all over the world who sing to young infants in an "infant-directed" singing style — using both lullaby and playsong style - which is probably used in order to express emotional information and to regulate their infant's state (Trainor and Schmidt 2003).

This brings us to the domain of feelings and emotions. Music, as a rule, has an emotive meaning which calls forth mechanisms of "affective semantics" with corresponding reactions which can vary between mild and strong emotional experiences (see Gabrielsson and Lindström 2001, Valzelli 2003: 4). A core assumption in this context is the role of the body and its physiological responses as a "theatre for emotional processing" and the mind-brain-body relationship in particular. It reminds us of James' view on the mechanisms of feelings and emotions (see Damasio 1994:129 for an extensive review) which strip the emotions down to a process that involves the body or the body sense that he considered to be the essence of the emotional response. To quote his famous words: "If we fancy some strong emotion and then try to abstract from our consciousness of it all the feelings of its bodily symptoms, we find we have nothing left behind, no "mind-stuff" out of which the emotion can be constituted, and that a cold and neutral state of intellectual perception is all that remains." (James 1901 [1890]: 451)

There has been a lot of controversy about this claim, which, for short, can be stated as the postulation of a mechanism in which particular stimuli in the environment excite - by means of an innate set of inflexible mechanisms - a specific pattern of body reactions. In this view, the body is the main stage for enactment of emotions, either direct or via its representation in somatosensory [415] structures in the brain. Feelings, accordingly, are considered to be reflections of body-state changes. 
One of the criticisms of this theory concerns the claim that we "always" use the body as a theatre for emotions. It is possible, in fact, to reenact emotions in emotional bodily states as well as to bypass this bodily enactment in a kind of “as if" devices. This latter mechanism is made possible through neural devices that help us feel "as if" we were having an emotional state, as if the body were being activated and modified. It means, further, that the brain learns to concoct the fainter image of an "emotional" body state without having to reenact it in the body proper (Damasio 1994: 155). These "as if" devices, however, are acquired only as the outcome of repeatedly associating the images of given entities or situations with the image of freshly enacted body states. In order, therefore, for the image to trigger the bypass device, the process must have been run or looped through the body theatre first (Damasio 1994: 156). It should be noticed, further, that emotional responses target both the body proper and the brain. The latter, especially, is able to produce major changes in neural processing that constitute a substantial part of what is perceived as a feeling (Damasio 2000: 288).

Another controversial point, according to Damasio (1994: 131), is James' claim that we do no need to "evaluate" the significance of the stimuli in order for the reaction to occur. This holds true for some primary or basic emotions that human beings experience early in life, and for which a Jamesian preorganised mechanism would suffice. They are easy to define - their listing embraces fear, anger, disgust, surprise, sadness, and happiness - and reflect the basically innate neural machinery that is required to generate somatic states in response to certain classes of stimuli. As such, they are inherently biased to process signals and to pair them with adaptive somatic responses with the processing proceeding in a preorganised fashion which relies on wired-in dispositions to respond with an emotional reaction when certain features of stimuli in the world or in our bodies are perceived. 
There are, however, other emotions that people experience in adult life and whose scaffolding has been built gradually on the foundations of these early emotions. These secondary emotions embrace reactions to a broad range of stimuli which are filtered by an interposed voluntary and mindful evaluation. As such, they allow room for variation in the extent and intensity of preset emotional patterns (Damasio 1994: 131).

The distinction is critical. According to Oatley, it stresses the hybrid position of emotional processing, where "nature meets nurture": emotive meaning can rely both on pre-programmed reactivity and on culturally established patterns or conventions of coping with the sound (1992:14). It is commonly agreed that human beings are wired-in to respond with an emotion to certain features of stimuli in the world, but emotional reactions cannot be exhaustively explained by pre-programmed reaction patterns alone.

This same evolutionary perspective conceives of "musical" emotions as adaptive responses which, according to Peretz, can be aroused silently in every human being as the product of neural structures that are specialised for their [417] computation. They can even be seen as reflexes in their operation, occurring with rapid onset, through automatic appraisal, and with involuntary changes in physiological and behavioural responses (Peretz 2001: 115). This explains also that we often experience emotions as "happening" to us, rather than chosen by us.

Further, there is evidence suggesting that emotional reactions to music do activate the same cortical, subcortical and autonomic circuits which are considered to be the essential survival circuits of biological organisms in general (Trainor and Schmidt 2003: 320). The cortical processing involves the higher 
functions of the brain; the subcortical processing affects the remainder of the body through the basic mechanisms of chemical release in the blood and the spread of neural activation. The latter, especially, incites people to react bodily to music with a whole bunch of autonomic reactions - changes in heart rate, respiration rate, blood flow, skin conductance, brain activation patterns, and even hormone release (oxytocin, testosterone)—which are induced by music or sound (see Becker 2001: 145, for an overview) and which are driven by the phylogenetically older parts of the nervous system. They can be considered to be the "physiological correlates" of listening to music and demonstrate convincingly that music does produce autonomic changes which are associated with emotion processing (Trainor and Schmidt 2003: 312).

Music, thus, "induces" emotions; it is not simply "about" emotions. It activates the autonomic system and physiological reactions can be demonstrated. There is, however, a distinction between mere physiological arousal and the interpretations or feelings that are the outcome of this arousal. As Damasio (1999: 79) puts it: we should distinguish between emotions and their resultant feelings, with the former referring to the autonomic nervous system arousal and the latter to the complex cognitive, culturally inflected interpretation of emotion. As such, it is possible to separate emotional arousal — which is clearly a universal response to musical listening - from the more cognitive concept of feelings which relate directly to fundaments and beliefs which are learned within a cultural context and which rely upon linguistics categories (Becker 2001: 145).

The question, then, arises which musical emotions can readily be distinguished as proper and distinct categories. Certain musical emotions can be categorised as happiness, sadness, anger, and fear, with the happy and sad emotional tones tending to be among the easiest ones to communicate in music (Gabrielsson and Juslin 1996, Krumhansl 1997). They might be expressed by similar structural 
features across musical styles and cultures, somewhat like facial expressions. The claim, nonetheless, is still somewhat tentative as the search of universals in the expression of musical emotions has just begun (see Balkwill and Thompson 1999; Juslin 2001). There is, however, increasing evidence that musical emotions are quickly and easily perceived by members of the same culture. Emotional judgements, as a rule, exhibit a high degree of consistence, suggesting that perception of emotions in music is natural and effortless for the large majority of listeners (Peretz 2001: 114).

It can be questioned, further, whether it is possible to relate specific emotional reactions to specific structural features of the music. In an attempt to tease out [418] some of them, Sloboda (1991) collected a list of features that produced particular physical emotional responses. A harmonic descending cycle of fifths to tonic, a melodic appoggiatura and a melodic or harmonic sequence all tend to produce a "tears" response. New or unprepared harmony seem to produce a "shivers" response. Another example is the finding by Schubert (1999) that the best predictor of arousal is loudness.

There is, finally, a difference between experiencing and recognising emotions, somewhat related to paradigms of emotion which rely on two broad systems for classifying them: categories and dimensions (Schubert 2001: 401). The "categorical" classification assumes that emotions which carry different meanings — happiness, sadness, anger, fear, disgust — are distinct and independent entities which can be labelled as one single category. The "dimensional" classification holds that all emotions are in some way related within an n-dimensional semantic space — or, more correctly, emotion spacewith as dimensions: valence, activity and arousal. Happy and sad, e.g., are opposite emotions along the valence dimension of emotion and sad and angry emotions express low and high arousal. 
As such, it is clear that there is a distinction between tapping only into the arousal dimension as a default response to music, and having an articulated emotional response. The latter, in fact, represents complex combinations of perceptual, cognitive and emotional aspects which brings us to the role of cognitive penetration in the process of dealing with music.

\subsection{The role of cognitive penetration}

Listening to music can be considered as a process that impinges upon innate mechanisms of coping with the sounds. Some of them act as lock-and-key and are likely to be induced by the music in a direct way. The human brain, however, is able to transcend its wired-in and reactive circuitry in order to build up new epistemic relations with its environment (Cariani 2001, 2003, Reybrouck 2005a). Understanding musical structures with at least some complexity, e.g., is not to be explained merely in terms of mere reactive machinery, but relies on higher levels of nervous activity that can determine the perceptual outcome and cognitive functioning as well. To quote Damasio:

"The evidence on biological regulation demonstrates that response selections of which organisms are not conscious and are thus not deliberated take place continuously in evolutionarily old brain structures. Organisms whose brains only include those archaic structures and are avoid of evolutionarily modern ones-reptiles, for instance - operate such response selections without difficulty.

One might conceptualize the response selections as an elementary form of decision making, provided it is clear that it is not an aware self but a set of neural circuits that is doing the deciding. [...] Yet it is also well accepted that when social organisms are confronted by complex situations and are asked to 
decide in the face of uncertainty, they must engage systems in the neocortex, the evolutionarily modern sector of the brain. “ (1994: 127)

[419] As soon as environments are getting more unpredictable and complex, however, the organism must not only rely on highly evolved genetically based biological mechanisms but also on suprainstinctual survival strategies that have developed in society and are transmitted by culture. The latter, as a rule, require consciousness, reasoned deliberation and willpower with response selections that are no longer reducible to the functioning of a set of neural circuits in the older structures of the brain.

Many perceptual phenomena, in this view, are cognitively penetrated, which means that the determination of the perceptual response depends on factors beyond the raw physical attributes of the stimulus (Uttal 1998: 3). This holds true for perception in general, which is not to be explained merely in reductionist terms which try to peripheralise the explanation of perception by locating the critical locus of perceptual experience in the earliest or lowest level of the sensory pathways. As Uttal puts it, there is simply no causal relation between sensory input and cognitive processing and resultant reactive behaviour: "stimuli do not lead solely and inexorably to responses by simple switching circuit-like behaviour". And further: "The main point is that "cognitive penetration" plays a very much more important role in perception than is often acknowledged, in particularly by those who seek to show the neural correlates of some psychophysical response. The ubiquity of cognitive penetration argues strongly that neuroreductionist strategies attributing perceptual experience to a few peripheral neurones will be hard to justify." (1998: 213) 
The only exception to these claims has been the centuries old trichotomy of the sensory-transformational-response mechanism with a grouping of cognitive processes into three classes: input, output and central transformation. There is, however, no convergence on a more detailed taxonomy (Uttal 2001: 145-147).

\section{Psychobiology and the mind-brain relationship}

There is a lot of freedom in the process of sense-making which is induced by the impingement of physical stimuli upon the sensory system. Yet there is a whole body of empirical research about sensory coding and wired-in reactivity to environmental stimulation which claims consistency in sensory responses. This has been the major claim of psychophysics, which should be seen as the exact science of the functional relations between the body and the mind (Fechner 1860). Being concerned basically with the relations between the dimensions of "physical stimuli" and the dimensions of "sensory experiences", it has made enormous progress towards an understanding of the information processing carried out by sensory systems. Sensory psychophysics, especially, has progressed considerably towards this understanding. It is one of the most mature of the psychobiological sciences (Uttal 1978: 16).

\section{[420] 5.1 Psychophysics and psychophysical elements}

Psychophysics, in its most narrow and traditional aspect, has concentrated on the psychological problem of judged magnitudes or intensities, with a major focus on the relationships between perceived magnitude and stimulus dimensions (Uttal 1978: 415). Its experimental paradigm has been the psychophysical experiment in which a single stimulus dimension (S) is manipulated and a single 
behavioural response dimension (R) measured (Uttal 1998: 199). The trouble, however, with this narrow conception is that it mistakes procedure for problems and precision for goals. Psychophysics, in this narrow sense, becomes synonymous with a few methods for the determination of thresholds (Stevens 1951: 31).

In its broader aspects, psychophysics can be seen as the science of the response of organisms to stimulating configurations. As such, it sees the responses as indicators of an attribute of the individual which vary with the stimulus and which are relatively invariant from person to person. As a science it tries to contribute to the "invariance" of the human nature in relying on seven major categories of psychophysical problems: (i) absolute thresholds (what are the stimulus values that mark the transition between response and no response?), (ii) differential thresholds (what is the resolving power of the organism, what is the smallest detectable change in a stimulus?), (iii) equality (what values of two different stimuli produce the same response or appear equal on the scale of some attribute?), (iv) order (what different stimuli produce a set of responses or psychological impression that can be set in serial order?), (v) equality of intervals (what stimuli produce a set of responses successively equidistant on the scale of some attribute?), (vi) equality of ratios (what stimuli produce a set of responses bearing constant ratio?) and (vii) stimulus rating (with what accuracy (validity) and precision (reliability) can a person estimate the "physical" value of a stimulus?) (Stevens 1951: 33).

It is easy to translate these psychophysical claims to the realm of music and to argue for some reliable correlation between acoustic signals and their perceptual processing. This correlation, further, embraces the conversion between the acoustic level of musical stimuli and the level of meaning, as well as the lawfulness or arbitrariness of this transformation. 
The use of the term "psychophysical" with respect to music, however, should be distinguished from its use in the broader field of psychophysics. Traditionally, the term refers to the relationship between a physical variable-like "decibels"- and a perceptual variable—like "perceived loudness" (see Boring 1942, for a historical perspective). The relationship may be a logarithmic function as described in Fechner's Law, or an exponential relationship as described in Stevens' Power Law (Stevens 1975). In the literature of music psychology, however, the term psychophysical has been used to refer to physical properties of music (e.g. tempo, pitch range, melodic complexity, rhythmic complexity) that may be defined and assessed independently of the musical conventions of any particular culture. It represents those qualities which are not restricted to a particular musical style or culture, and which do not require [421] detailed musical knowledge in order to interpret them or respond to them at an emotional level (Balkwill 1997: 3-4). They mainly correspond to those characteristics of music to which basic auditory processes naturally respond (e.g. tempo/pulse speed). Tempo is an example: it can be measured in beats per minute (bpm), which is a quantifiable measure of occurrence over time which could apply to any type of stimulus.

As such, there have been attempts to list up psychophysical elements of music. For the assessment of emotional content of Western music, e.g., the following elements have been summed up: tempo, modality, melodic contour, harmonic complexity, melodic complexity, rhythmic complexity, articulation, dynamics, consonance/dissonance, pitch register, and timbre (Holbrook and Anand 1990, Gabrielsson and Juslin 1996, Gerardi and Gerken 1995, Kratus 1993, Nielzén and Cesarec 1982, Scherer and Oshinsky 1977, see Balkwill 1997: 13 for an overview). 


\subsection{Psychobiology and its major claims}

The transition from physical or acoustical stimuli to mental experiences is a psychobiological problem. It revolves around the single axiom that the external world is represented within the organisms by patterns of neural activity. A main goal of psychobiology, therefore, is to integrate psychology and neurophysiology into one unified "monistic" framework which reduces sensory and psychological activities to patterns of neural activity (Uttal 1973: 6). This neural reductionism aims at discovering how the brain makes neural patterns in its nerve-cell circuits and how it manages to turn them into mental patterns (Damasio 2000: 9). As such, it tries to establish the psychoneural equivalents of perceptual responses and mental experiences.

Rather than being concerned with the relationship between the stimulus and the neural responses - the neurophysiological search for neural codes - or with the relationship between the stimulus and the total systems behaviour of the organism - the psychological claim-, psychobiology is concerned with the classic mind-body problem itself, namely the relationship between the neural response dimension and the dimensions of experience (Uttal 1973: 213). This is, in fact, the basic reductionism of the psychobiological axiom that psychological properties arise out of physiological processes, and that it is possible to seek explanations of psychological functions by observing the underlying physiological processes (Uttal 1978: 10).

The three main themes of psychobiology, therefore, address three fundamental questions: (i) the localisation of function in the brain (a problem at the macroanatomical level: where in the brain are particular processes mediated?), (ii) the representation or coding (a problem at the microanatomic level: how do 
neural networks represent, encode, or instantiate cognitive processes?) and (iii) the dynamic change or learning (how does our brain adapt to experience, what [427] changes occur in its neural networks as a result of experience, and how do these changes correspond to externally observed behaviour?) (Uttal 1978: XV, 2001: 2). The questions point into the direction of neurobiological research.

\section{The neurobiological approach}

The last decades have brought a depth of understanding about the mind-brain relationship that goes beyond the more intuitive approaches of previous research. Scholars can now rely on empirical evidence from both neuroimaging and morphometric studies in order to elucidate brain areas which mediate both the production and perception of music. As such, it is possible to refine the findings in three major domains: (i) localisation studies which try to find anatomical markers for musical skills, (ii) studies on the role of neural plasticity and (iii) the search for structural and functional adaptation of the brain as the result of musical experience, both at a macrostructural and microstructural level.

\subsection{Brain and mind: towards a new phrenology}

Localisation studies are typical of physiological psychology and modern cognitive neuroscience. They aim at relating mental functions to particular structures or localised regions of the brain and give, in a way, new impetus to the former science of phrenology - a theory which claimed to be able to determine the character, personality traits and even criminology on the basis of the shape of the head. This science is mainly considered to be a pseudoscience with many historical aberrations, but nevertheless, it has received some credit 
as a protoscience for the finding that some brain areas can be related to specific mental functions.

Neuromusicology, similarly, is in continuous search of anatomical markers of typical or special skills (see Altenmüller 2003: 347). It has been profoundly influenced by the idea of the modularity of mind (Fodor 1983, 1985, Gardner 1983, see Peretz and Morais 1989 for musical applications) which conceives of "modules" as specialised computational devices that are devoted to the execution of some biologically important functions. According to Fodor, it is possible to conceive of input systems as modular systems, relying on a whole bunch of arguments which all define the scope of modular functions: an input system is defined by a separate sensory modality; our awareness of sensory messages is obligatory; we are able to perceive only the input or output system without having knowledge of the codes or interpretative processes that led to a particular perception; the speed of perception precludes processing analyses; the system is relatively impermeable to cognitive, topdown influences; an input system is clearly associated with particular receptors, structures and regions of the brain; when it breaks down, it produces highly specific behavioural [423] distortions; and the ontogeny of the input system seems to be very similar from one person to another (Fodor 1983, see also Uttal 2001: 115).

It is possible also to conceive of a kind of modularity of musical functions with as controlling assumption that mental processes are analysable into distinct and separable modules. The assumption is twofold. It is related, first, to the topic of musical capacities or competencies, which should constitute a set of aptitudes or innate capacities with proper functions that depend very little on particular conditions of concrete training during childhood and adulthood (Imberty 2004: 450). An additional postulate, secondly, is that these competencies have their equivalence in the internal functioning of the brain, which should mean that they 
correspond to defined and independent modular neuronal systems. We should be careful, however, not to generalise too quickly about modular functions with respect to music. According to Imberty (2004), they pertain only to those aspects of music which are probably the least developed and least musical.

There have been several attempts, further, to solve the localisation problem: mapping mental functions and their localisation in the brain (functional brain mapping studies), investigating the acquisition of new skills and the corresponding neural changes which are associated with their mastering, and studying the effects of brain lesion in patients. The most important sources of information, however, have been provided by the ever-expanding array of studies which use both "structural" and "functional" brain-imaging techniques. They have been able to assign specific brain areas that mediate both the production and perception of music — including tonal, rhythmic, and emotive aspects of music processing (see Brown 2000: 17, for an overview). Musical skills or competencies, further, are multifaceted, they involve motor, auditory and visual regions of the brain. We should be careful, however, not to confuse perceptual and performing skills in dealing with music, as both rely on different areas of the brain.

Some musical abilities, finally, have neural correlates and the asymmetry or dominance of certain homologue structures in the brain points in the direction of functional implications (Schlaug 2001:296). More in general, there are wellknown hypotheses which assign analytical, step-by-step processing to the left frontotemporal brain regions and the more global way of processing and visuospatial associations to the right frontal and bilateral parietooccipital lobes (Altenmüller 2003: 349). As to the musical skills, the findings suggest that there are distinct neural subsystems - separate modules so to speak - for the processing of pitch discrimination and time discrimination. Some key brain 
areas in the distributed neural circuits underlie the perceptual and cognitive representation of central aspects of musical rhythm such as musical metre, tempo, pattern and duration (Parsons 2003: 260), while other areas underlie other aspect of music processing. Generally speaking, time structure seems to be processed to a greater extent in the left temporal lobe whereas pitch structure may be processed primarily in right temporal and supratemporal lobe networks (Altenmüller 2003: 347).

More in particular, there is the prominent role of the planum temporale in the left superior temporal lobe of the human brain. Its surface area has long been taken as a structural marker for left hemisphere language dominance in righthanders - it is found to be asymmetric in normal right-handed samples with a greater leftward bias-, but this same structure is also involved in auditory processing of musical stimuli. As such, it is of great interest for studies investigating the laterality of auditory processing with as major finding that musicians with absolute pitch - the ability to identify the pitch of any tone in the absence of a musical context or reference tone - show an increased left-sided asymmetry of the planum temporale. Its functional significance probably must be seen in the context of their ability to assign any pitch to a verbally labelled pitch class - this is categorical perception - which, in turn, influences the recognition memory for pitch (Keenan et al. 2001:1402, Schlaug 2001). Other cortical areas play a particular role in the temporal control of sequential motor tasks and their integration in bilateral motor behaviour - as in key and string players. Areas that have been established involve motor related regions such as the premotor and cerebellar cortex and the supplementary motor area of the cortex (Schlaug 1995: 1048). 
A somewhat related finding is the observation that there is a pattern of differences in the grey matter distribution between professional musicians, amateur musicians and non-musicians (Gaser and Schlaug 2003: 9244).

\subsection{Neural plasticity and the role of adaptation}

Localisation studies may seem both seductive and promising. Much of the "localisation research" effort, however, is seriously misleading as well. According to Uttal, it has been based on incorrect assumptions that cannot be validated either in principle or in practice (Uttal 2001: 205, 214). It is argued, further, that localisation of high-level cognitive functions in specific regions of the brain is not achievable. In spite of some major accomplishments in the field of perception and motor behaviour, the picture is changing gradually from a rather static conception of particular brain modules to a dynamic conception of reorganisational plasticity of the adult cortex (see Pantev et al. 2003: 383).

Adaptability, however, is not working in a vacuum. It is triggered by challenging environments which are able to modify the design of our brain circuitries. There are, further, two mechanisms that shape our interactions with the environmental world: the recruitment of more and more evolutionary younger structures of the brain as environments get more unpredictable and complex, and structural and functional adaptations of the brain tissue as the outcome of interactions with the world (Damasio 1994: 111-112).

Experiences, according to Damasio, cause synaptic strengths to vary within and across neural systems. They shape our neural design, not only as the outcome of our first experiences, but throughout the whole life span. Connections between neurones are built primarily during cerebral maturation processes in childhood, 
but even later in their life humans respond with considerable flexibility to new challenges. This means that the connectivity of the adult brain is only partially determined by genetics and early development, with a major role for modification through sensory experiences. The neural circuits, in other words, [425] are not totally pregiven and wired-in but are repeatedly pliable and modifiable by continued experience (Damasio 1994: 112, Pantev et al. 2003: $381)$.

Neural plasticity, in this view, may lead to use-dependent regional growth and structural adaptation in cerebral grey matter in response to intense environmental demands (Gaser \& Schlaug 2003: 9244). The basic principles are based on Hebb's ideas that learning may alter synaptic connectivity. In what is commonly known as "Hebb's rule", it is asserted that effective connections between neurones are formed depending on synchronous activation: "Cells that fire together, wire together" (Hebb 1949, see also Pantev et al 2003: 383). What really matters are changes of synaptic efficacy with the conjunction of pre- and postsynaptic activity contributing to a strengthening of synaptic connections (Rauschecker 2003: 357). The organisation of the brain thus seems capable of significant change to adapt to the changing demands of the environment, mainly as the result of an augmented simultaneous stimulation of neurones, which entrains a reorganisation of the functional neuronal networks in the brain. Our cerebral cortex, in other words, has the ability to self-organise in response to extrinsic stimuli.

All this holds also true for the process of dealing with music, with performing musicians as a typical example. Their unique training and practice involves both co-ordination and synchronisation of somatosensory and motor control on the one hand and audition on the other hand, along with the ability to memorise long and complex bimanual finger sequences, to translate musical symbols into motor 
sequences (sight-reading), and to perceive and identify tones absolutely in the absence of a reference tone (absolute pitch) (Pantev et al. 2003: 38, Schlaug 2001). Musicians, therefore, can be used as an ideal subject pool to investigate the plastic nature of the human brain and to study functional and structural adaptation of the motor and auditory system in response to extraordinary challenges which involve the unique requirements of skilled performance.

\subsection{Structural and functional adaptations}

The plastic changes in the brain that are the outcome of enhanced musical experience can be found at two levels: the gross-anatomical differences between professional musicians with absolute pitch and amateurs or laymen, and the subtle functional differences after musical training, which have to be sought in ever finer modifications of synaptic strength in distributed cortical networks (Rauschecker 2003: 357). As such, it is possible to distinguish between macrostructural and microstructural adaptations.

It makes a difference, further, whether musical experience is meant to be "active performance" or only "listening" to music. The plastic changes that are triggered by playing a musical instrument are numerous and well-documented. They include changes such as the rapid unmasking of existing connections and the establishment of new ones. As such, both functional and structural changes take place in the brain in an attempt to cope with the demands of the activity of [425] skilful playing (see Pascual-Leone 2003: 396). Some of these changes, however, are triggered by listening as well.

As far as the macrostructural changes are concerned, there are changes which are the outcome of instrumental playing, such as a difference in a measure of 
primary motor cortex size (Amunts et al. 1997: 210). Other findings are related to the planum temporale, the corpus callosum and some representation areas.

The planum temporale, first, shows an increased leftward symmetry in musicians with absolute pitch recognition. There is, however, no agreement as to the development of this skill. Two critical notions relate to early exposure to music: almost all musicians with absolute pitch started musical training before the age of 7 and is it unlikely that an individual will develop absolute pitch if he/she commences musical training after the age of 11 (Keenan 2001: 1406).

The corpus callosum, secondly, is the main inter hemispheric fibre tract that plays an important role in interhemispheric integration and communication. Its midsagittal size correlates with the number of fibres passing through this structure. In spite of its late development - it is one of the last main fibre tracts to mature in humans - increases in corpus callosum size have been observed until at least the third decade of human life. The maximal growth, however, is in the first decade which is the period of presumed callosal maturation which coincides with childhood increases in synaptic density and fine tuning of the neural organisation. It has been proposed, further, that environmental stimuli, especially early in life, might affect callosal development (Lee et al. 2002: 205).

The corpus callosum, further, has been found to be larger in performing musicians who started their musical training before the age of 7 . This adaptation can be interpreted as a morphological substrate of increased interhemispheric communication between frontal cortices (such as the premotor and supplementary motor cortex) subserving complex bimanual motor sequences (Schlaug 1995: 1050). Somewhat generalising, it could be stated that environmental factors - such as intense bimanual motor training of musicianscould play an important role in the determination of callosal fibre composition 
and size, which, in turn, can be considered as an adaptive structural-functional process. It remains to be determined, however, whether the large corpus callosum of musicians with early commencement of training contains a greater total number of fibres, thicker axons, more axon collaterals, stronger myelinated axons, or a higher percentage of myelinated axons (Schlaug 1995: 1050-1051).

The microstructural adaptations, finally, must be located at the level of individual neurones and synapses. They reflect the functional plasticity of the brain which can lead to microstructural changes which have been found both as the result of brain lesion (deafferentiation) and motor skill learning, and which aim at changing the efficacy of the neural connectivity.

As to the first, it has been shown that there is some cortical remodelling which is induced by deafferentiation. This includes microstructural changes such as the strengthening of existing synapses, the formation of new synapses (synaptogenesis), axonal sprouting and dendrite growth (Pantev et al. 2003: 385). As to the latter, there are similar significant microstructural changes which [427] are induced in motor-related brain regions as a consequence of intense and prolonged motor activity. The adaptations include an increased number of synapses per neurone as well as changes in the number of microglia, and capillaries, which can lead to volumetric changes detectable at a macrostructural level (Hutchinson 2003: 943, Schlaug 2001: 283).

It is clear that the brain may show some form of adaptation to extraordinary challenges. This is the case with the requirements for musical performance, which may cause some brain regions to adapt. The adaptation, however, does not always involve plastic structural changes. Musical expertise, in fact, influences auditory brain activation patterns, and changes in these activation patterns depend on the teaching strategies applied. To quote Altenmüller: “ 
...brain substrates of music processing reflect the auditory learning 'biography', the personal experiences accumulated over time. Listening to music, learning to play an instrument, formal instruction, and professional training result in multiple, in many instances multisensory, representations of music, which seem to be partly interchangeable and rapidly adaptive." (Altenmüller 2003: 349)

\section{Conclusion}

In this contribution I have argued for a broadening of the scope of traditional music research. I have stressed the role of the "music user" besides the music, relying heavily on a "processual approach" to music which conceives of music users as organisms that cope with their environment. Rather than thinking of music as a structure or artefact, I have emphasised the music user's mechanisms of sense-making and knowledge construction. This is basically an ecological approach to cognition which considers the organism-environment interactions in a continuous attempt to make sense out of the perceptual flux.

Musical sense-making, accordingly, is shaped by previous and current interactions with the sonic world. There is a whole dispositional machinery which is coded in our genetic programs with reactions relying on pre-wired and innate neural circuitry. As such, it is possible to consider the biological grounding of musical epistemology. The musical code, in this view, holds a hybrid position between nature and nurture with as major questions: what is wired-in and what is acquired?

In order to answer these questions, I have elaborated on the contributions from psychophysics and psychobiology, which provide a lot of empirical evidence as to the topic of sensory coding. Their major claims evolve around the central 
axiom of "psychobiological equivalence" between percepts, experience and thought. They address the central question whether there is some lawfulness in the co-ordinations between sounding stimuli and the responses of music users in general. The answer is not obvious: there are psychophysical commonalities which can be considered to be universal, but there is a lot of subjectivity as well. It makes sense, therefore, to conceive of biological, perceptual and ecological [428] constraints which act as "biases", rather than to think in terms of "causal relationships" between sounding stimuli and reactions to these stimuli. It allows us, further, to consider the idiosyncrasies of the individual music user in his/her attempts to make sense out of the sounding flux, and to conceive of the process of sense-making in terms of epistemic autonomy.

As such, there should be a dynamic tension between the "nature" and the "nurture" side of music processing, stressing the role of the musical "experience proper". Music, in fact, is a sounding and temporal art which has inductive power. The latter involves ongoing epistemic interactions which rely on lowlevel sensory processing as well as on principles of cognitive economy, with the former referring to the nature side, and the latter to the nurture side of music processing. Cognitive processing, however, should be "coperceptual" in order to take into account the full richness of the sensory experience. What I argue for, therefore, is the reliance on the nature side again, which ends up, finally, in what I call the "nature-nurture-nature sequence" of music processing.

\section{References}

Altenmüller, E. (2003). How Many Music Centres Are in the Brain? In: Peretz, I. \& R.Zatorre (Eds.). (2003). The Cognitive Neuroscience of Music Oxford - New York: Oxford University Press, pp. 346-353. 
Amunts, K., Schlaug, G., Jäncke, L., Steinmetz, H., Schleicher, A., Dabringhaus, A. \& Zilles, K. (1997). Motor Cortex and Hand Motor Skills: Structural Compliance in the Human Brain. Human Brain Mapping, 5, 206-215.

Arom, S. (2000). Prolegomena to a Biomusicology. In Wallin, N., B.Merker \& S.Brown (Eds.) (2000). The Origins of Music. Cambridge, MA - London: The MIT Press, pp. 27-29.

Balkwill, L.-L. (1997). Perception of emotion in music: a cross-cultural investigation. Unpublished doctoral dissertation. North York: York University.

Balkwill, L.-L. \& Thompson, W. (1999). A cross-cultural investigation of the perception of emotion in music: Psychophysical and cultural cues. Music Perception, 17, 43-64.

Barbieri, M. (2005). Life is "artifact-making”. Journal of Biosemiotics, 1, 113142.

Barkow, J.H., Cosmides, L. \& Tooby, J. (1992). The Adapted Mind:

Evolutionary Psychology and the Generation of Culture. Oxford: Oxford University Press.

Bateson, G. (1985). Mind and Nature. London: Fontana Paperbacks.

Bateson, G. (1978 [1973]). Steps to an Ecology of Mind. Paladin: London Toronto - Sydney - New York - Granada.

Bechterew V.M. (1933/1917). General principles of human reflexology: An Introduction to the Objective Study of Personality. New York: International Publishers (Transl. by E.Murphy \& W.Murphy).

Becker, J. (2001). Anthropological perspectives on music and emotion. In: Juslin, P.N. \& J.Sloboda (Eds.) (2001). Music and Emotion: Theory and Research. Oxford: Oxford University Press, pp. 135-160.

Berlin, B. \& Kay, P. (1969). Basic Color Terms: Their Universality and Evolution. Berkeley - Los Angeles: University of California. 
Berne, E. (1964). Games people play. New York: Grove Press.

Blacking, J. (1973). How Musical is Man? Seattle: Universtiy of Washington Press.

Blacking, J. (1995). Music, Culture, and Experience: Selected Papers of John Blacking. R.Byron (Ed.). Chicago: University of Chicago Press.

Boring, E.G. (1942). Sensation and Perception in the History of Experimental Psychology. New York: Appleton-Century-Crofts.

Bregman, A. (1981). Asking the "what for" question in auditory perception, in:

M.Kubovy \& J.Pomerantz (Eds.) (1981). Perceptual Organization,

Hillsdale, NJ: Lawrence Erlbaum Associates, pp. 99-118.

Bregman, A. (1990). Auditory Scene Analysis: The Perceptual Organization of Sound. Cambridge, MA: The MIT Press.

Brier, S. (1999b). Biosemiotics and the Foundations of Cybersemiotics,

Semiotica, 127 (1/4), 169-198.

Brown, D. (1991). Human Universals. New York: McGraw-Hill.

Brown, S., Merker, B. \& Wallin, N. (2000). An Introduction to Evolutionary

Musicology. In Wallin, N., B.Merker \& S.Brown (Eds.) (2000). The

Origins of Music. Cambridge, MA - London: The MIT Press, pp. 3-24.

Bystrina, I. (1983). Kodes und Kodewandel. Zeitschrift für Semiotik, 5, 1-22.

Cariani, P. (1998). Life's journey through the semiosphere. Semiotica, 120-3/4, pp. 243-257.

Cariani, P. (2003). Cybernetic Systems and the Semiotics of Translation. In S.Petrilli (Ed.), Translation Translation. Amsterdam: Rodopi (pp. 349 $367)$.

Cariani, P. (2001). Symbols and dynamics in the brain, Biosystems, 60, 1-3, 59-

83. Special issue on "Physics and evolution of symbols and codes".

Chomsky, N. (1965). Aspects of the Theory of Syntax. Cambridge, MA: MIT.

Clynes, M. (1977). Sentics: The Touch of Emotion. London: Souvenir Press. 
Cross, I. (2003). Music, Cognition, Culture, and Evolution. In Peretz, I. \& R.Zatorre (Eds.). 2003). The Cognitive Neuroscience of Music. Oxford New York: Oxford University Press, pp. 42-56.

Damasio, A. (1994). Descartes' Error: Emotion, Reason, and the Human Brain. New York: Harper Collins.

Damasio, A. (2000). The Feeling of What Happens. Body and Emotion in the Making of Consciousness. London: Vintage.

Damasio, A. (2004). Looking for Spinoza. Joy, Sorrow and the Feeling Brain. London: Vintage.

Dawkins, R. (1976). The Selfish Gene. Oxford: Oxford University Press.

Deschênes, B., (1991). Music and the new scientific theories. International Review of the Aesthetics and Sociology of Music, 22, 2, 193-202.

Drake, C. \& Bertrand, D. (2003). The Quest for Universals in Temporal Processing in Music. In Peretz, I. \& R.Zatorre (Eds.). 2003). The Cognitive Neuroscience of Music. Oxford - New York: Oxford University Press, pp. 21-31.

Durham, W. (1991). Coevolution: Genes, Culture and Human Diversity. Stanford, CA: Stanford University Press.

Ekman, P. (1972). Universals and cultural differences in facial expressions of emotion. In J. Cole (Ed.) (1972). Nebraska Symposium on Motivation. Lincoln: University of Nebraska Press, pp. 207-283.

Ekman, P. (1992). An argument for basic emotions. Cognition and Emotion. 6, 169-200.

Ekman, P. (1992). Facial expressions of emotions: New Findings, new questions. Psychological Science, 3: 34-38.

Fechner, T. (1860). Elemente der Psychophysik. Leipzig: Breitkopf and Härtel. Fodor, J. (1983). The Modularity of Mind. Cambridge, MA: MIT Press. Fodor, J. A. (1985). Précis of The Modularity of Mind. Behavioral and Brain Sciences, 8, 1-42. 
Frayer, D.W. \& Nicolay, C. (2000). Fossil Evidence for the Origin of Speech Sounds. In Wallin, N., B.Merker \& S.Brown (Eds.) (2000). The Origins of Music. Cambridge, MA - London: The MIT Press, pp. 271-300.

Frick, R. (1985). Communicating emotion: The role of prosodic features. Psychological Bulletin, 97, 412-429.

Gabrielsson, A., \& Juslin, P. N. (1996). Emotional expression in music performance: Between the performer's intention and the listener's experience. Psychology of Music, 24,68-91.

Gabrielsson, A. \& Lindström, E.. (2001). The Influence of Musical Structure on Emotional Expression. In: Juslin, P.N. \& J.Sloboda (Eds.). (2001) Music and Emotion: Theory and Research (pp. 223-248). Oxford: Oxford University Press.

Gardner, H. (1983). Frames of Mind. The Theory of Multiple Intelligences. New York: Basic Books.

Gaser, Ch. \& Schlaug, G. (2003), Brain Structures Differ between Musicians and Non-Musicians. The Journal of Neuroscience, 23 (27), pp. 9240-9245.

Geertz, C. (1983). Blurred genres: The refiguration of social thought. In: C.Geertz (1983). Local knowledge: Further essays in interpretative anthropology. New York: Basic Books, pp. 19-35.

Gerardi, G. M. \& Gerken, L. (1995). The development of affective responses to modality and melodic contour. Music Perception. 12(3), 279-290.

Gibson, J. (1961). Outline of a New Attempt to Classify the Senses and the Sensory Inputs. Unpublished manuscript. www.huwi.org/gibson/classify.php

Gibson, J. (1966). The Senses Considered as Perceptual Systems. London, Allen \& Unwin, 1966.

Gibson, J. (1979). The Ecological Approach to Visual Perception. Boston Dallas - Geneva - Illinois - Hopewell - New Jersey - Palo Alto - London: Houghton Mifflin Company. 
Gibson, J. (1982). Reasons for Realism: Selected Essays of James J.Gibson,

E.Reed and R.Jones (Eds.), Hillsdale, NJ: Lawrence Erlbaum.

Goddard, C. (2002). The search for the shared semantic core of alle languages.

In C.Goddard \& A.Wierzbicka (Eds.). Meaning and Universal Grammar -

Theory and Empirical Findings. Volume I. Amsterdam: John Benjamins (pp. 5-40).

Goldschmidt, W. (1959). Man's Way: A Preface to the Understanding of

Human Society. New York: Holt.

Greenberg, H. (Ed.) (1963). Universals of language. Cambridge, MA - London: MIT Press.

Hauser, M., Chomsky, N. \& Fitch, W.T. (2002). The Faculty of Language: What Is, Who Has It, and How Did It Evolve? Science, 298, 1570-1579.

Hebb, D.O. (1949). The Organization of Behavior. New York: Wiley.

Hevner, K. (1935a). Expression in music: A discussion of experimental studies and theories. Psychological Review, 42,186-204.

Hevner, K. (1935b). Experimental studies of the elements of expression in music. American Journal of Psychology, 48, 248-268.

Holbrook, M. B. \& Anand, P. (1990). Effects of tempo and situational arousal on the listener's perceptual and affective responses to music. Psychology of Music, 18(2), 150-162.

Huron, D. (2003). Is Music an Evoltionary Adaptation? In: Peretz, I. \& R.Zatorre (Eds.). (2003). The Cognitive Neuroscience of Music. Oxford New York: Oxford University Press, pp. 57-75.

Hutchinson, S., Hui-Lin Lee, L., Gaab, N. \& Schlaug, G. (2003). Cerebellar Volume in Musicians. Cerebral Cortex, 13, 943-949.

Imberty, M. (2004). The Question of Innate Competencies in Musical Communication. In Wallin, N, B.Merker \& S.Brown (Eds.) (2000). The Origins of Music. Cambridge, MA - London: The MIT Press, pp. 449-462. 
James, W. (1901 [1890]). The Principles of Psychology. Vol.1., London: Macmillan.

Jerison, H. (2000). Paleoneurology and the Biology of Music. In Wallin, N., B.Merker \& S.Brown (Eds.) (2000). The Origins of Music. Cambridge, MA - London: The MIT Press, pp. 177-196.

Juslin, P. (2001). Communicating Emotion in Music Performance: A Review of and Theoretical Framework. In: Juslin, P.N. \& J.Sloboda (Eds.). (2001) Music and Emotion: Theory and Research. Oxford: Oxford University Press( pp. 309-337)..

Juslin, P. \& Sloboda, J. (2001a). Music and emotion: Introduction. (pp. 3-20). In: Juslin, P.N. \& J.Sloboda (Eds.). (2001b) Music and Emotion: Theory and Research. Oxford: Oxford University Press.

Juslin, P.N. \& Sloboda, J. (Eds.) (2001b). Music and Emotion: Theory and Research. Oxford: Oxford University Press.

Keenan, J. P., Thangaraj, V., Halpern, A. \& Schlaug, G. (2001). Absolute Pitch and Planum Temporale, NeuroImage, 14, 1402-1408.

Koffka, K. (1935). Principles of Gestalt Psychology. New York: Harcourt Brace.

Köhler, W. (1947). Gestalt psychology: An introduction to new concepts in modern psychology. New York: Liveright.

Kornilov, K. N. (1930). Psychology in the light of dialectical materialism. In C. Murchison (Ed.). Psychologies of 1930. Worcester, MA: Clark University Press.

Krechevsky, I. (1932a). Hypotheses in rats. Psychological Review, 39, 516532.

Krechevsky, I. (1932b). "Hypothesis" versus "chance" in the presolution period in sensory discrimination learning. University of California Publications of Psychology, 6, 27-44. 
Krechevsky, I. (1932c). The hereditary nature of "hypothesis". Journal of Comparative Psychology, 16, 99-116.

Kratus, J. (1993). A developmental study of children's interpretation of emotion in music. Psychology of Music, 21, 3-19.

Krumhansl, C. (1997). An exploratory study of musical emotions and psychophysiology. Canadian Journal of Experimental Psychology, 51, 336-353.

LeDoux, J.E. (1996). The Emotional Brain: The Mysterious Underpinnings of Emotional Life. New York: Simon and Schuster.

Lee, H. (1938). Perception and Aesthetic Value, New York, Prentice-Hall.

Leech, G.L. (1974). Semantics. Middlesex, England: Penguin Books.

Leman, M. (1999). Naturalistic Approaches to Musical Semiotics and the Study of Causal Musical Signification. In: I.Zannos (Ed.), Music and Signs, Semiotic and Cognitive Studies in Music, ASCO Art \& Science, Bratislava, pp. 11-38.

Levine, M. and Shefer, J. (1981). Fundamentals of Sensation and Perception. Pacific Grove, CA: Brooks-Cole Publishing Co.

Liberman, M. Y. (1975). The intonational system of English. Bloomington: Indiana University Linguistics Club.

Luhmann, N. (1990). Essays on Self-Reference. New York: Columbia University Press.

Luhmann, N. (1995). Social Systems. Stanford, CA: Stanford University Press.

Lumsden, C. \& Wilson, E. (1981). Genes, Mind and Culture. Cambridge: Harvard University Press.

Mâche, F.-B. (2000). The Necessity of and Problems with a Universal Musicology. In Wallin, N, Merker, B. \& S.Brown (Eds.) (2000). The Origins of Music. Cambridge, MA - London: The MIT Press, pp. 473-479. 
Maturana, H. (1978). Biology of language: the Epistemology of Reality, in: G.Miller \& E.Lenneberg (Eds.), Psychology and biology of language and thought. New York: Academic Press; pp; 27-46.

Maturana, H. \& Varela, F. (1980). Autopoiesis and Cognition: The Realization of the Living. London: Reidel.

Meystel, Alex (1998). Multiresolutional Umwelt: Towards a semiotics of neurocontrol. Semiotica, 120, 3/4, pp. 343-380.

Miller, G. (2000). Evolution of human music through sexual selection. In: N.L.Wallin, B.Merker, and S.Brown (Eds.). The Origins of MusicCambridge, MA: MIT Press, pp. 329-360.

Molino, J. (2000). Toward an Evolutionary Theory of Music and Language, In Wallin, N., B.Merker \& S.Brown (Eds.) (2000). The Origins of Music. Cambridge, MA - London: The MIT Press, pp. 165-176.

Mowbray, R. \& Rodger, T. (1963). Psychology in Relation to Medicine. Edinburgh - London: Lingstone.

Murdock, G.P. (1945). The Common Denominator of Cultures, in: R.Linton (Ed.). (1945). The Science of Man in the World Crisis. New York: Columbia University Press, pp. 123-142.

Neisser, U. (1967). Cognitive Psychology. New York: Appleton-Century Crofts.

Nettl, B. (2000). An Ethnomusicologist Contemplates Universals in Musical Sound and Musical Cultures. In Wallin, N, B.Merker \& S.Brown (Eds.) (2000). The Origins of Music. Cambridge, MA - London: The MIT Press, pp. 463-479).

Nielzén, S., \& Cesarec, Z (1982). Emotional experience of music as a function of musical structure. Psychology of Music. 10(2), 7-17.

Paillard, J. (1994). L'intégration sensori-motrice et idéo-motrice. In M.Richelle, J.Requin \& M.Robert (1994). Traité de psychologie expérimentale.1, Paris: Presses Universitaires de France, pp. 925-996. 
Pantev, C., Engelien,A., Candia, V \& Elbert, T. (2003). Representational Cortex in Musicians. In: Peretz, I. \& R.Zatorre (Eds.). 2003). The Cognitive Neuroscience of Music. Oxford - New York: Oxford University Press, pp. 381-395.

Parsons, L. (2003). Exploring the Functional Neuroanatomy of Music Performance, Perception, and Comprehension. In: Peretz, I. \& R.Zatorre (Eds.). 2003). The Cognitive Neuroscience of Music. Oxford - New York: Oxford University Press, pp. 247-268.

Pascual-Leone, A. (2003). The Brain that Makes Music and is Changed by it. In: Peretz, I. \& R.Zatorre (Eds.). (2003). The Cognitive Neuroscience of Music. Oxford - New York: Oxford University Press, pp. 396-409). Pask, G. (1961a). An Approach to Cybernetics. Science Today Series. New York: Harper \& Brothers.

Pask, G. (1961b). The cybernetics of evolutionary processes and of selforganizing systems. Namur. Third International Conference on Cybernetics, Namur, Belgium, 27-74.

Pask, G. (1992). Different kinds of Cybernetics. In: van de Vijver, G. (Ed.), New Perspectives on Cybernetics: Self-Organization, Autonomy and Connectionism. Dordrecht: Kluwer Academic, pp. 11-31.

Pavlov, I. (1960/1927). Conditioned Reflexes: An Investigation of the Phyisological Activity of the Cerebral Cortex. (Transl. and ed. by G.V.Anrep). New York: Dover.

Peretz, I. (2001). Listen to the brain: a biological perspective on musical emotions. In: Juslin, P.N. \& J.Sloboda (Eds.). (2001) Music and Emotion: Theory and Research. (pp. 105-134). Oxford: Oxford University Press.

Peretz, I. \& Morais, J. (1989). Music and modularity. Contemporary Music Review, 4, 277-291.

Pinker, S. (2002). The Blank Slate. New York: Viking Press.

Pinker, S. (1994). The Language Instinct. New York: Morrow. 
Pomerantz, J.R. (1986). Visual form perception: An overview. In E. Schwab \& H. Nusbaum (Eds.), Pattern recognition by humans and machines: Visual perception (Vol.2, pp. 1-30). Orlando, FL: Academic.

Port, R. \& Leary, A. (2005). Against formal phonology. Language, 81 (4): 927964.

Rauschecker, J.P. (2003). Functional Organization and Plasticity of Auditory Cortex. In: Peretz, I. \& R.Zatorre (Eds.). 2003). The Cognitive Neuroscience of Music. Oxford - New York: Oxford University Press, pp. 357-365.

Reybrouck, M. (1997). Gestalt Concepts and Music: Limitations and Possibilities, in: M. Leman (Ed.), Music, Gestalt and Computing. Studies in Cognitive and Systematic Musicology, Springer Verlag, Berlin -Heidelberg, pp.57-69.

Reybrouck, M. (1999). The musical sign between sound and meaning, in: I.Zannos (Ed.), Music and Signs, Semiotic and Cognitive Studies in Music, ASCO, Art \& Science, Bratislava, pp.39-58.

Reybrouck, M. (2001a). Biological roots of musical epistemology: Functional Cycles, Umwelt, and enactive listening. Semiotica, 134, 1-4, 599-633 Reybrouck, M. (2001b). 'Musical Imagery between Sensory Processing and Ideomotor Simulation', in R.I.Godøy \& H.Jörgensen (Eds.), Musical Imagery, Swets \& Zeitlinger, Lisse, pp. 117-136.

Reybrouck, M. (2003b). Musical semantics between epistemological assumptions and operational claims. In: E.Tarasti (Ed.)., Musical Semiotics Revisited (pp. 272-287). Acta Semiotica Fennica XV. Imatra: International Semiotics Institute.

Reybrouck, M. (2004). Music Cognition, Semiotics and the Experience of Time. Ontosemantical and Epistemological Claims. Journal of New Music Research, 33, 4, pp. 411-428. 
Reybrouck, M. (2005a). A Biosemiotic and Ecological Approach to Music Cognition: Event Perception between Auditory Listening and Cognitive Economy. Axiomathes. An International Journal in Ontology and Cognitive Systems, 15, 2, pp. 229-266.

Reybrouck, M. (2005b). Body, mind and music: musical semantics between experiential cognition and cognitive economy. Trans. Transcultural Music Review, 9 <http://www.sibetrans.com/trans/> [ISSN:1697-0101]. 46 pp.

Reybrouck, M. (2006a). Music Cognition and the Bodily Approach: Musical Instruments as Tools for Musical Semantics. Contemporary Music Review, 25, 1/2, pp. 59-68.

Reybrouck, M. (2006b). Musical Creativity between Symbolic Modelling and Perceptual Constraints: the Role of Adaptive Behaviour and Epistemic Autonomy. In: I.Deliège é G.Wiggins (Eds.). Musical Creativity: Multidisciplinary Research in Theory and Practice. Oxford: Psychology Press, pp. 42-59.

Reybrouck, M. (2006c). The listener as an adaptive device: an ecological and biosemiotical approach to musical semantics. In: E.Tarasti (Ed.). Music and the Arts. Acta Semiotica Fennica XXIII - Approaches to Musical Semiotics 10. Imatra: International Semiotics Institute - Helsinki: Semiotic Society of Finland. (pp. 106-116)..

Rosenberg, L. \& Adelstein, B. (1993). Perceptual Decomposition of Virtual Haptic Surfaces. In: Proceedings IEEE 1993 Symposium on Research Frontiers in Virtual Reality (pp. 46-53). San Jose, CA, October 1993. Scherer, K.R., \& Oshinsky, J.S. (1977). Cue utiiization in emotion attribution from auditory stimuli. Motivation and Emotion, 1, 331-346.

Scherer, K.R \& Zentner, KR (2001). Emotional effects of music: production rules. In P. N. Juslin \& J. A. Sloboda (Eds). Music and emotion: Theory and researc.h Oxford: Oxford University Press, pp. 361-392. 
Schlaug, G. (1995). Increased corpus callosum size in musicians.

Neuropsychologia, 33 (8), 1047-1055.

Schlaug, G. (2001). The Brain of Musicians. A Model for Functional and Structural Adaptation. In Zatorre, R. \& I.Peretz (Eds.)., (2001). The Biological Foundations of Music. New York: Annals of the New York Academy of Sciences, Vol. 930, pp. 281-299.

Schubert, E. (1999). Measuring emotion continuously: Validity and reliability of the two dimensional emotion space. Australian Journal of Psychology, 51, 154-165.

Schubert, E. (2001). Continuous measurement of self-report emotional response to music. In: Juslin, P.N. \& J.Sloboda (Eds.). Music and Emotion: Theory and Research. (pp. 393-414). Oxford: Oxford University Press.

Seifert, U. (1993). Systematische Musiktheorie und Kognitionswissenschaft. Zur Grundlegung der kognitiven Musikwissenschaft. Bonn: Verlag für systematische Musikwissenschaft.

Sekuler, R., \& Blake, R. (1985). Perception. New York: Alfred J.Knopf.

Sloboda, J. (1991). Music structure and emotional response: Some empirical findings. Psychology of Music, 19, 110-120.

Sloboda, J. \& Juslin, P. (2001). Music and emotion: commentary. In : Juslin, P. \& J. Sloboda, J. (Eds.). (2001). Music and Emotion: Theory and Research. Oxford: Oxford University Press, pp. 453-462.

Stevens, S. (1951). Mathematics, Measurement, and Psychophysics, in:

Stevens, S. (Ed.). (1951). Handbook of Experimental Psychology. New York-London: Wiley - Chapman \& Hall, pp. 1 - 49.

Stevens, S.S. (1975). Psychophysics: Introduction to its perceptiial, neural and social prospects. New York: John Wiley.

Trainor, L.J. \& Schmidt, L.A. (2003). Processing Emotions Induced by Music. In: Peretz, I. \& R.Zatorre (Eds.). (2003). The Cognitive Neuroscience of Music. Oxford - New York: Oxford University Press, pp. 310-324. 
Trehub, S. (2000). Human Processing Predispositions and Musical Univerals. In Wallin, N., B.Merker \& S.Brown (Eds.) (2000). The Origins of Music. Cambridge, MA - London: The MIT Press, pp. 427-448.

Trehub, S. (2003). Musical predispositions in infancy: an update. In: Peretz, I. \&R.Zatorre (2003), The Cognitive Neuroscience of Music. Oxford: Oxford University Press, pp. 3-20.

Uttal, W. (1973). The Psychobiology of Sensory Coding. New York - Evanston - San Francisco - London: Harper \& Row.

Uttal, W. (1978). The Psychobiology of Mind. Hillsdale, NJ: Lawrence Erlbaum. Uttal, W. (1981). A Taxonomy of Visual Processes. Hillsdale, NJ: Lawrence Erlbaum Associates.

Uttal, W. (1998). Toward a New Behaviorism. The Case Against Perceptual Reductionism. Mahwah (NJ) - London: Lawrence Erlbaum Publishers. Uttal, W. (2001). The New Phrenology. The Limits of Localizing Cognitive Processes in the Brain. Cambridge (MA - London: The MIT Press. Valzelli, M. (1981). Psychobiology of Aggression and Violence, New York, Raven Press, 1981.

van Rooij, R. (2005). Evolutionary motivations for semantic universals. Paper presented at the Blankensee conference, Berlin, summer 2005.

von Foerster, H. (1974) (Ed.). Cybernetics of Cybernetics, Illinois: University of Illinois.

von Foerster, H. (1984). Observing Systems. Seaside, CA: Intersystems Press.

Wallin, N. (1991), Biomusicology. Neurophysiological and Evolutionary Perspectives on the Origins and Purposes of Music. New York: Pendragon Press.

Wallin, N., Merker, B. \& Brown, S. (Eds.) (2000). The Origins of Music. Cambridge, MA - London: The MIT Press

Wertheimer, M. (1923). Untersuchungen zur Lehre von der Gestalt, II. Psychologische Forschung, 4, 301-350. Translated as Laws of organization 
in perceptual forms. In W.D. Ellis (Ed.). (1955), A source book of Gestalt psychology. London: Routledge \& Kegan Paul.

Wierzbicka, A. (1996). Semantics: Primes and Universals. Oxford: Oxford University Press. 